\title{
Intercomparison of stratospheric gravity wave observations with AIRS and IASI
}

\author{
L. Hoffmann ${ }^{1}$, M. J. Alexander ${ }^{2}$, C. Clerbaux ${ }^{3}$, A. W. Grimsdell ${ }^{2}$, C. I. Meyer ${ }^{1}$, T. Rößler ${ }^{1}$, and B. Tournier ${ }^{4}$ \\ ${ }^{1}$ Forschungszentrum Jülich, Jülich Supercomputing Centre, Jülich, Germany \\ ${ }^{2}$ NorthWest Research Associates, Inc., CoRA Office, Boulder, CO, USA \\ ${ }^{3}$ Sorbonne Universités, UPMC Univ. Paris 06, Université Versailles St-Quentin, CNRS/INSU, LATMOS-IPSL, Paris, France \\ ${ }^{4}$ Noveltis, Labège, France \\ Correspondence to: L. Hoffmann (1.hoffmann@fz-juelich.de)
}

Received: 8 August 2014 - Published in Atmos. Meas. Tech. Discuss.: 19 August 2014

Revised: 10 November 2014 - Accepted: 13 November 2014 - Published: 18 December 2014

\begin{abstract}
Gravity waves are an important driver for the atmospheric circulation and have substantial impact on weather and climate. Satellite instruments offer excellent opportunities to study gravity waves on a global scale. This study focuses on observations from the Atmospheric Infrared Sounder (AIRS) onboard the National Aeronautics and Space Administration Aqua satellite and the Infrared Atmospheric Sounding Interferometer (IASI) onboard the European MetOp satellites. The main aim of this study is an intercomparison of stratospheric gravity wave observations of both instruments. In particular, we analyzed AIRS and IASI $4.3 \mu \mathrm{m}$ brightness temperature measurements, which directly relate to stratospheric temperature. Three case studies showed that AIRS and IASI provide a clear and consistent picture of the temporal development of individual gravity wave events. Statistical comparisons based on a 5-year period of measurements (2008-2012) showed similar spatial and temporal patterns of gravity wave activity. However, the statistical comparisons also revealed systematic differences of variances between AIRS and IASI that we attribute to the different spatial measurement characteristics of both instruments. We also found differences between day- and nighttime data that are partly due to the local time variations of the gravity wave sources. While AIRS has been used successfully in many previous gravity wave studies, IASI data are applied here for the first time for that purpose. Our study shows that gravity wave observations from different hyperspectral infrared sounders such as AIRS and IASI can be directly related to each other, if instrument-specific characteristics such as different noise levels and spatial resolution and
\end{abstract}

sampling are carefully considered. The ability to combine observations from different satellites provides an opportunity to create a long-term record, which is an exciting prospect for future climatological studies of stratospheric gravity wave activity.

\section{Introduction}

Gravity waves play a key role in atmospheric dynamics and have substantial impact on weather and climate. They transport energy and momentum, contribute to turbulence and mixing, and influence the mean circulation and thermal structure of the middle atmosphere (Lindzen, 1981; Holton, $1982,1983)$. In the stratosphere, gravity waves are particularly important in the summer hemisphere where planetary wave activity is weak (Alexander and Rosenlof, 1996; Scaife et al., 2000). The most prominent sources of gravity waves are orographic generation (Smith, 1985; Durran and Klemp, 1987; Nastrom and Fritts, 1992; Dörnbrack et al., 1999) and convection (Pfister et al., 1986; Tsuda et al., 1994; Alexander and Pfister, 1995; Vincent and Alexander, 2000). Other sources include adjustment of unbalanced flows near jet streams and frontal systems as well as body forcing accompanying localized wave dissipation (Fritts and Alexander, 2003; Vadas et al., 2003; Wu and Zhang, 2004). The individual characteristics of the wave sources and the evolution of the wave spectrum with altitude-dependent wind and stability variations are important research topics today. 
Satellite instruments offer an excellent opportunity to study gravity waves on a global scale. The main advantage of limb sounders and occultation measurements is good vertical resolution, which allows sensitivity to gravity waves with short vertical wavelengths. In contrast, nadir sounders are limited to longer vertical wavelengths, but they provide better horizontal resolution. Infrared nadir observations of gravity waves with long vertical wavelengths and short horizontal wavelengths as studied here are of particular interest because these waves can potentially carry large momentum flux and can excite significant wave drag (Fritts and Alexander, 2003; Ern et al., 2004; Preusse et al., 2008; Gong et al., 2012). A particular problem for all satellite measurements is that each instrument can observe only parts of the full gravity wave spectrum due to the different observation geometries and spectral coverages (Wu et al., 2006; Preusse et al., 2009b; Alexander et al., 2010). Nevertheless, both limb and nadir satellite observations can help to validate low-frequency and long-wavelength gravity waves that are explicitly resolved in mesoscale models and to validate gravity wave parametrization schemes in general circulation models (Alexander and Barnet, 2007; Alexander et al., 2010; Geller et al., 2013).

This study focuses on nadir observations of two instruments, the Atmospheric Infrared Sounder (AIRS) onboard the National Aeronautics and Space Administration's Aqua satellite and the Infrared Atmospheric Sounding Interferometer (IASI) onboard the European MetOp satellites. We analyze radiance measurements, in particular the $4.3 \mu \mathrm{m}$ brightness temperatures in the $\mathrm{CO}_{2}$ fundamental band, which can be directly related to stratospheric temperature. The $15 \mu \mathrm{m}$ waveband of $\mathrm{CO}_{2}$ offers another choice for gravity wave studies. As the 4.3 and $15 \mu \mathrm{m}$ measurements usually have different characteristics in terms of vertical coverage, sensitivity, and noise, they can be considered complimentary to each other. Our study focuses on the $4.3 \mu \mathrm{m}$ measurements because these have not been studied extensively before. Analyzing retrieved temperatures rather than radiance measurements is an alternative approach for studying gravity waves. However, retrievals for nadir instruments such as AIRS and IASI are mostly designed for meteorological applications that focus on the troposphere. Retrievals for the stratosphere have only limited data quality and are not extensively validated. A particular advantage of using AIRS radiances instead of retrieved temperatures is that radiance data are available at the nominal sampling grid. In contrast, AIRS operational temperature retrievals have degraded horizontal resolution as $3 \times 3$ footprints are combined within a cloud-clearing procedure before the retrieval. Hoffmann and Alexander (2009) developed a dedicated retrieval scheme for high-resolution stratospheric temperature data from AIRS to overcome some of these problems. However, no comparable data set is available for IASI.

AIRS radiance measurements have been successfully exploited for a large number of gravity wave studies. For instance, Alexander and Teitelbaum (2007),
Eckermann et al. (2007),

Limpasuvan et al. (2007), Alexander and Teitelbaum (2011), Niranjan Kumar et al. (2012), and Jiang et al. (2013) used AIRS data to study orographic waves at hotspots like the Antarctic Peninsula, the Andes, the Greenland topography, and the Himalayas. Eckermann et al. (2009), Lambert et al. (2012), and Orr et al. (2014) used AIRS observations to study the impact of mountain waves at high latitudes on the formation of polar stratospheric clouds. Hecht et al. (2009), Kim et al. (2009), Grimsdell et al. (2010), Choi et al. (2012), and Yue et al. $(2013,2014)$ used AIRS data for case studies of convective waves related to deep convection and hurricanes. Furthermore, AIRS data have also been applied in several climatological studies of stratospheric gravity wave activity. Hoffmann and Alexander (2010) presented a climatology of convective waves during the North American thunderstorm season. Eckermann and Wu (2012) discuss orographic gravity-wave activity in the winter subtropical stratosphere over Australia and Africa. Gong et al. (2012) presented the first global climatology of gravity wave variances from AIRS. Alexander and Grimsdell (2013) studied the seasonal cycle of orographic gravity wave occurrence above small islands in the Southern Ocean. Hoffmann et al. (2013) used AIRS data to identify local hotspots of stratospheric gravity wave activity on a global scale.

In contrast, IASI data have not been used for gravity wave research so far. Yet, the measurement characteristics of AIRS and IASI are quite similar. Both instruments operate in nearly polar, sun-synchronous low-earth orbits, have across-track scanning capabilities with similar spatial sampling patterns, and provide hyperspectral radiance measurements covering the mid-infrared spectral region. For gravity wave research, it is promising that AIRS and IASI take measurements at different local time, with Equator crossing times around 01:30 and 09:30, respectively. Combined observations potentially provide a much clearer picture of the temporal development of individual gravity wave events than a single instrument alone. In this study we performed comparisons of AIRS and IASI to assess how the stratospheric gravity wave observations of both instruments relate to each other. We aimed to characterize and compare the sensitivity to gravity waves with different vertical and horizontal wavelengths. We carefully estimated and corrected for the varying instrument noise levels at different scene temperatures. The presentation in this paper covers AIRS and IASI observations for three case studies of orographic and convective waves. The case studies illustrate the individual performance of AIRS and IASI regarding observations of gravity waves from different sources with distinct wave characteristics. Our study also covers statistical comparisons of time series and seasonal maps of gravity wave variances based on a 5-year period of measurements (2008-2012). The statistical analyses allow us to assess which parts of climatological gravity wave activity both instruments are capable of observing. 
In Sect. 2, we provide brief descriptions of the AIRS and IASI instruments and the method used to extract gravity wave information from the radiance measurements. In Sect. 3, we present the results of our study, including the AIRS and IASI gravity wave observations for three case studies and the statistical comparisons. In Sect. 4, we discuss the results, compare with findings of other recent studies, and summarize our conclusions.

\section{Data and methods}

\subsection{AIRS and IASI observations}

The Atmospheric Infrared Sounder (AIRS) (Aumann et al., 2003; Chahine et al., 2006) is one of six instruments onboard the National Aeronautics and Space Administration (NASA) Aqua satellite. Aqua was launched in May 2002 and is part of NASA's Earth Observing System. It is the first satellite in the "A-Train" constellation of satellites. AIRS has been in nearly continuous operation since launch. The Infrared Atmospheric Sounding Interferometer (IASI) (Blumstein et al., 2004; Clerbaux et al., 2009; Hilton et al., 2012) is a key payload element of the MetOp series of European meteorological satellites. The first flight model, IASI-A, was launched in October 2006 onboard MetOp-A. A second instrument, IASI-B on MetOp-B, was launched in September 2012. A third instrument will be launched in 2018 on MetOpC. Here we focus on data from the IASI-A instrument onboard MetOp-A, which is referred to as IASI on MetOp in this paper.

The Aqua and MetOp orbit parameters as well as the spatial and spectral measurement characteristics of AIRS and IASI are summarized in Table 1. Both Aqua and MetOp operate in nearly polar, sun-synchronous orbits. The orbit altitudes are 705 and $817 \mathrm{~km}$, respectively. Both satellites have an orbit period of about $100 \mathrm{~min}$ and an orbit inclination of about $100^{\circ}$. Global coverage is achieved during 14.4 orbits per day. The individual local times of the Aqua and MetOp orbits as a function of latitude are compared in Fig. 1. Both satellites provide coverage at fixed local times. The Equator crossing of the ascending orbits occurs around 01:30 p.m. for Aqua and 09:30 p.m. for MetOp, i.e., the ascending orbits provide daytime measurements for AIRS and nighttime measurements for IASI. For the descending orbits it is the reverse. At high latitudes, there is a quick transition in local time.

AIRS and IASI both measure infrared radiance spectra from the earth's atmosphere in the nadir and sub-limb observation geometry. AIRS applies a rotating mirror to carry out scans in the across-track direction. A scan consists of 90 footprints and covers an across-track distance of $1780 \mathrm{~km}$ on the ground. The along-track distance between two scans is $18 \mathrm{~km}$. The across-track sampling distance varies between $13 \mathrm{~km}$ at nadir and $42 \mathrm{~km}$ at the scan extremes. The footprint

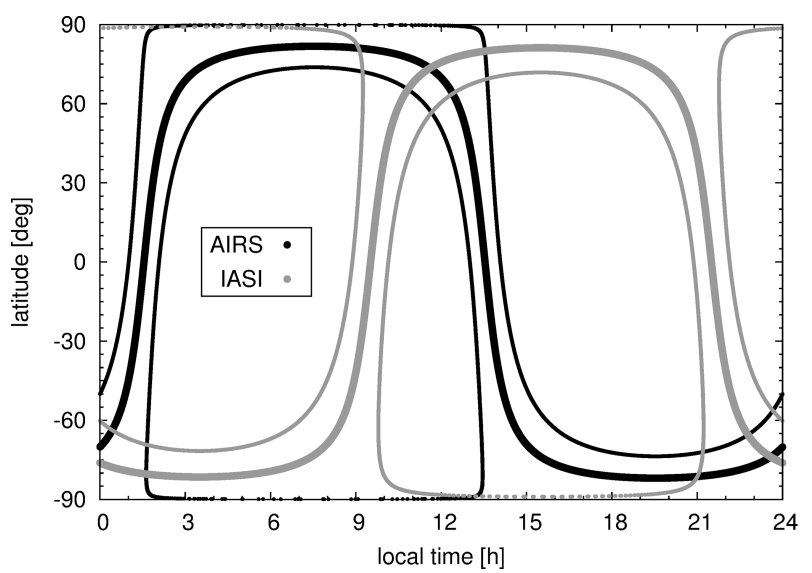

Figure 1. Local time versus latitude of AIRS and IASI observations. Thick curves represent the nadir measurement track. Thin curves represent the outermost measurement tracks. AIRS and IASI have sun-synchronous orbits, which combine orbit altitude and inclination in such a way that the satellite ascends or descends over any given latitude at the same local time. The orbit parameters stay constant over the time period of the mission

size is $13.5 \mathrm{~km}$ at nadir. IASI has nearly the same maximum scan angle as AIRS (about $\pm 50^{\circ}$ ), but due to the larger orbit altitude the IASI swath covers an across-track distance of $2100 \mathrm{~km}$. A nominal IASI scan line covers 30 scan positions, and for each of these scan positions IASI takes measurements in a $2 \times 2$ block of footprints. For this study we rearranged the $30 \times 2 \times 2$ footprints from an individual IASI scan into a $60 \times 2$ (across-track $\times$ along-track) pattern to get a sampling grid similar to AIRS. However, the IASI scan pattern is more irregular than the AIRS scan pattern because there is a larger distance between each $2 \times 2$ block than inside a $2 \times 2$ block. The across- and along-track sampling distances of IASI vary between 18 and $89 \mathrm{~km}$ and 18 and $38 \mathrm{~km}$, respectively. The footprint size is $12 \mathrm{~km}$ at nadir. The AIRS and IASI scan patterns are illustrated in Fig. 2. The plot shows that spatial sampling and resolution may have a significant impact on observations of short-scale gravity waves. AIRS measures spectra for 2.9 million footprints per day. IASI provides data for 1.3 million footprints per day.

Both AIRS and IASI provide hyperspectral mid-infrared radiance data. AIRS employs a diffraction grating spectrometer and a set of 17 linear arrays of $\mathrm{HgCdTe}$ detectors for that purpose. The radiance measurements cover the wavelength ranges from 3.74 to $4.61 \mu \mathrm{m}$, from 6.20 to $8.22 \mu \mathrm{m}$, and from 8.8 to $15.4 \mu \mathrm{m}$. The nominal resolving power is $\lambda / \Delta \lambda=$ 1200. The noise equivalent delta temperature (NEDT) at $250 \mathrm{~K}$ scene temperature varies between 0.07 and $0.7 \mathrm{~K}$. The processing of the instrument raw data into calibrated radiance spectra (Level-1B data) and the validation of these data are discussed by Aumann et al. (2000, 2003), Pagano et al. (2003, 2008), and Elliott et al. (2013). The IASI instrument uses a Fourier transform spectrometer and three detec- 
Table 1. Aqua and MetOp Orbit Parameters and AIRS and IASI Measurement Characteristics.

\begin{tabular}{|c|c|c|}
\hline & AIRS/Aqua & IASI-A/MetOp-A \\
\hline \multicolumn{3}{|l|}{ Satellite orbit parameters } \\
\hline Launch date & 4 May 2002 & 19 October 2006 \\
\hline Orbit altitude & $705 \mathrm{~km}$ & $817 \mathrm{~km}$ \\
\hline Orbit period & $98 \mathrm{~min}$ & $101 \mathrm{~min}$ \\
\hline Orbit inclination & $98.2^{\circ}$ & $98.7^{\circ}$ \\
\hline Local time of ascending node & 01:30 p.m. & 09:30 p.m. \\
\hline \multicolumn{3}{|l|}{ Instrument spatial characteristics } \\
\hline Footprints per day ${ }^{\mathrm{a}}$ & 2916000 & 1277000 \\
\hline Scans per day ${ }^{b}$ & 32400 & 21280 \\
\hline Footprints per scan & 90 & 60 \\
\hline Scan angle (from nadir) & $\pm 49.5^{\circ}$ & $\pm 48^{\circ}$ \\
\hline Swath width & $1780 \mathrm{~km}$ & $2100 \mathrm{~km}$ \\
\hline Across-track sampling distance & $13 \ldots 42 \mathrm{~km}$ & $18 \ldots 89 \mathrm{~km}$ \\
\hline Along-track sampling distance & $18 \mathrm{~km}$ & $18 \ldots 38 \mathrm{~km}$ \\
\hline Footprint size (nadir) & $13.5 \mathrm{~km}$ & $12 \mathrm{~km}$ \\
\hline \multicolumn{3}{|l|}{ Instrument spectral characteristics } \\
\hline Spectral range & $650 \ldots 2665 \mathrm{~cm}^{-1}$ & $645 \ldots 2760 \mathrm{~cm}^{-1}$ \\
\hline Band gaps & $\begin{array}{l}1135 \ldots 1215 \mathrm{~cm}^{-1} \\
1615 \ldots 2180 \mathrm{~cm}^{-1}\end{array}$ & none \\
\hline Spectral resolution & $0.54 \ldots 2.2 \mathrm{~cm}^{-1}$ & $0.5 \mathrm{~cm}^{-1}$ \\
\hline Spectral sampling & $0.27 \ldots 1.1 \mathrm{~cm}^{-1}$ & $0.25 \mathrm{~cm}^{-1}$ \\
\hline Noise (NEDT at $250 \mathrm{~K}$ ) & $0.07 \ldots 0.7 \mathrm{~K}$ & $0.08 \ldots 2.7 \mathrm{~K}$ \\
\hline
\end{tabular}

a For IASI we refer to the instantaneous fields of view (IFOV) as "footprints". b For IASI we rearranged the $30 \times 2 \times 2$ IFOV of a scan line into a $60 \times 2$ sampling pattern.

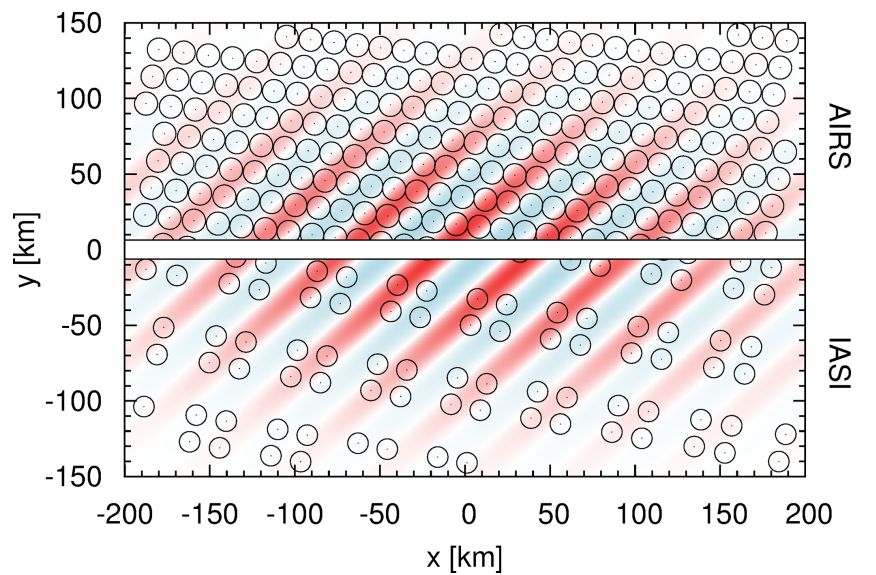

Figure 2. Illustration of the scan patterns of AIRS (upper half of plot) and IASI (lower half) close to the nadir direction. The contour surface in the background shows a wave pattern with $50 \mathrm{~km}$ horizontal wavelength. Circles show individual footprints (diameter represents their size). We refer to the distance between the footprints as "spatial sampling" and we refer to the size of the footprints as "spatial resolution". tor packages for radiance measurements between 3.62 and $15.5 \mu \mathrm{m}$. It covers nearly the same spectral range as AIRS, but does not have band gaps. The IASI spectra are apodized with a Gaussian spectral response function (Level-1C data) and have $0.25 \mathrm{~cm}^{-1}$ spectral sampling and $0.5 \mathrm{~cm}^{-1}$ spectral resolution. The IASI NEDT varies between 0.08 and $2.7 \mathrm{~K}$ at $250 \mathrm{~K}$ scene temperature. Data processing and validation of IASI radiance data are discussed by Simeoni et al. (2004), Blumstein et al. (2007), Illingworth et al. (2009), and Larar et al. (2010).

\subsection{Gravity wave analysis}

Our study of stratospheric gravity waves based on AIRS and IASI radiance measurements follows the approach of Hoffmann and Alexander (2010) and Hoffmann et al. (2013). In particular, we analyze the $4.3 \mu \mathrm{m} \mathrm{CO}_{2}$ fundamental band, which becomes optically thick in the middle stratosphere and provides direct information on stratospheric temperatures. For each satellite footprint we calculate the spectral mean brightness temperature over two spectral ranges from 2322.5 to $2346.0 \mathrm{~cm}^{-1}$ and from 2352.5 to $2367.0 \mathrm{~cm}^{-1}$. The small gap between these two ranges was excluded as it contains channels that include signals from the troposphere. 

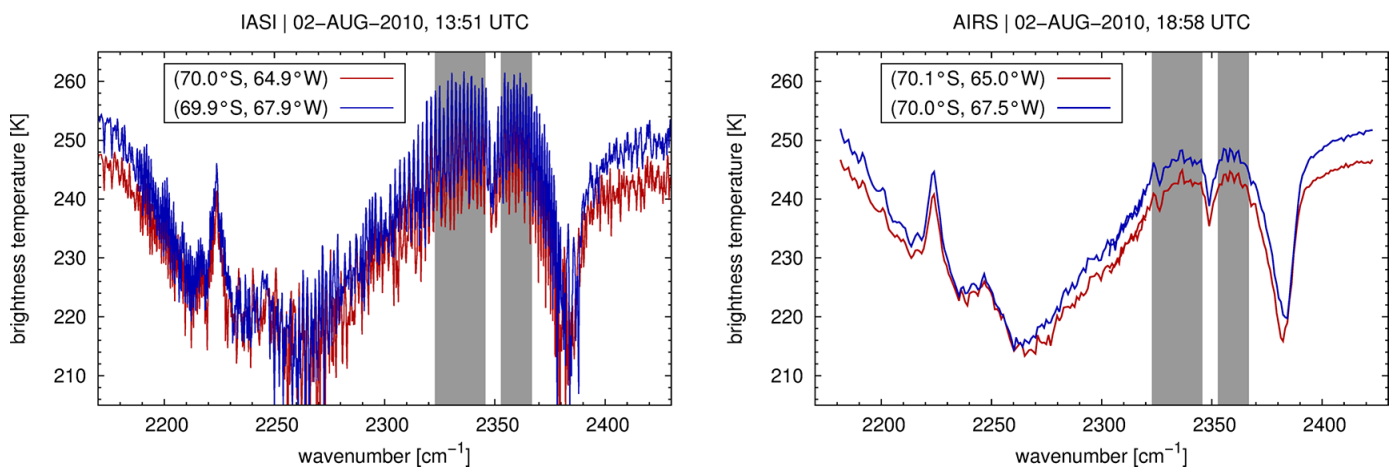

Figure 3. IASI (left) and AIRS (right) radiance spectra measured during a mountain wave event at the Antarctic Peninsula on 2 August 2010. Red and blue curves show spectra measured at nearly the same time and latitude, but separated by $100 \mathrm{~km}$ zonal distance (half wavelength of mountain wave). Spectral mean radiances in the gray shaded regions are analyzed for stratospheric gravity waves.

As an example of the influence of stratospheric gravity waves on individual AIRS and IASI measurements, Fig. 3 shows radiance spectra measured by AIRS and IASI during a mountain wave event on 2 August 2010 near the Antarctic Peninsula. This event will be discussed in more detail in Sect. 3.1. Fig. 3 shows spectra from AIRS and IASI that are measured at nearly the same time and latitude, but separated by about $100 \mathrm{~km}$ zonal distance (about half the wavelength of the mountain wave). As can be seen on the plots, the mountain wave is causing differences of $5 \mathrm{~K}$ in the $4.3 \mu \mathrm{m}$ brightness temperatures on average. Note that IASI has much higher spectral resolution than AIRS at $4.3 \mu \mathrm{m}$ and that the instrument is capable of resolving individual $\mathrm{CO}_{2}$ lines.

The spectral ranges used in this analysis were initially selected for AIRS, based on the similarity of their temperature kernel functions. Figure 4 compares the individual and spectral mean temperature kernel functions for AIRS and IASI within the selected spectral ranges. In contrast to AIRS, the IASI kernel functions show substantial variation in peak height and width. The diversity of the AIRS and IASI kernel functions is due to the different spectral resolutions of both instruments at $4.3 \mu \mathrm{m}$. IASI has better spectral resolution and can resolve individual $\mathrm{CO}_{2}$ lines. As a consequence, differences in optical depth between line centers and line wings become visible in the kernel functions. However, as we are analyzing spectral mean radiances, only the spectral mean kernel functions of both instruments are of further interest. Figure 4 shows that the spectral mean kernel functions of AIRS and IASI are quite similar. They both have a broad maximum in sensitivity at 30 to $40 \mathrm{~km}$ altitude and a full-width at half-maximum of about $25 \mathrm{~km}$. This means that AIRS and IASI provide similar vertical coverage regarding the gravity wave observations at $4.3 \mu \mathrm{m}$. Note that the sensitivity to temperature drops to near zero below $20 \mathrm{~km}$ altitude. Tropospheric emissions from interfering species like water vapor, from clouds, or from the surface are therefore not expected to influence the $4.3 \mu \mathrm{m}$ measurements in most cases. The only exception we found are daytime scenes with very large contrasts between land- and sea-surface temperatures. These scenes occur near the coasts of desert areas and may have surface temperature differences up to $40 \mathrm{~K}$ between neighboring pixels. For these scenes we found minor biases (up to $0.1 \mathrm{~K}$ ) between the pixels in the $4.3 \mu \mathrm{m}$ measurements as well. This specific case needs to be treated carefully or should be excluded from gravity wave analyses.

A major objective of this study is a statistical comparison of AIRS and IASI $4.3 \mu \mathrm{m}$ brightness temperature variances due to stratospheric gravity wave activity. The observed $4.3 \mu \mathrm{m}$ brightness temperatures are mainly composed of contributions from three sources. These sources are (i) slowly varying background signals, (ii) gravity waves, and (iii) noise. Accordingly, the total brightness temperature variance $\sigma_{\text {tot }}^{2}$ is given by

$\sigma_{\text {tot }}^{2}=\sigma_{\mathrm{bg}}^{2}+\sigma_{\mathrm{gw}}^{2}+\sigma_{\text {noise }}^{2}$,

with background variance $\sigma_{\mathrm{bg}}^{2}$, gravity wave variance $\sigma_{\mathrm{gw}}^{2}$, and noise variance $\sigma_{\text {noise }}^{2}$. In order to extract the gravity wave signals we must first remove the background signals. The background signals are associated with large-scale gradients in temperature with latitude and planetary-scale waves. Another strong background signal is the "limb-brightening effect" that refers to an increase in radiance with increasing scan angle due to elongated atmospheric ray paths. The background signals are removed by means of a local "detrending" procedure, which was described in detail by Wu (2004), Eckermann et al. (2006), and Alexander and Barnet (2007). In this procedure the background is estimated as a fourthorder polynomial fit in the across-track direction for each scan. Brightness temperature perturbations are calculated as differences from the polynomial fit. Note that this detrending procedure will suppress wave components with wave fronts parallel to the across-track direction. Along-track smoothing of the background may help in this case, but we found that it can introduce problems in regions where there are strong latitudinal gradients in the temperature field, e.g., at the polar vortex edge, and we did not consider it here. 

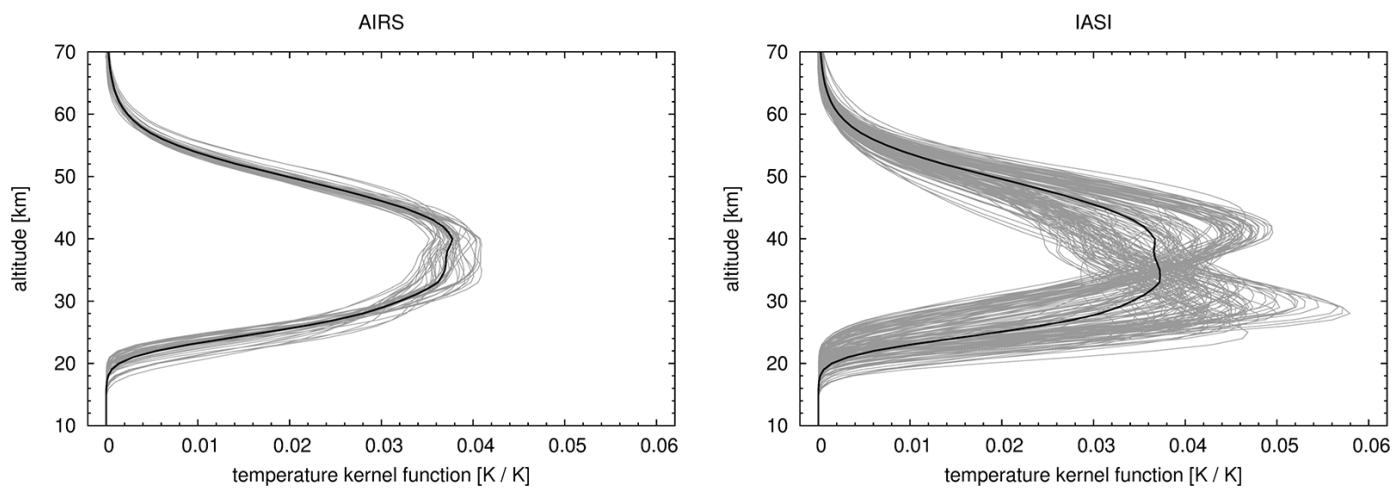

Figure 4. Temperature kernel functions for the $4.3 \mu \mathrm{m} \mathrm{CO}$ fundamental band for AIRS (left) and IASI (right). Gray curves show kernel functions for individual channels within spectral ranges from 2322.5 to $2346.0 \mathrm{~cm}^{-1}$ and 2352.5 to $2367.0 \mathrm{~cm}^{-1}$. Black curves show spectral mean kernel functions. Kernel functions were calculated for a mid-latitude reference atmosphere and the nadir geometry. Note that the absolute values of the kernel functions depend on the vertical grid spacing $(1 \mathrm{~km})$ and interpolation scheme (linear) applied in the radiative transfer calculations.
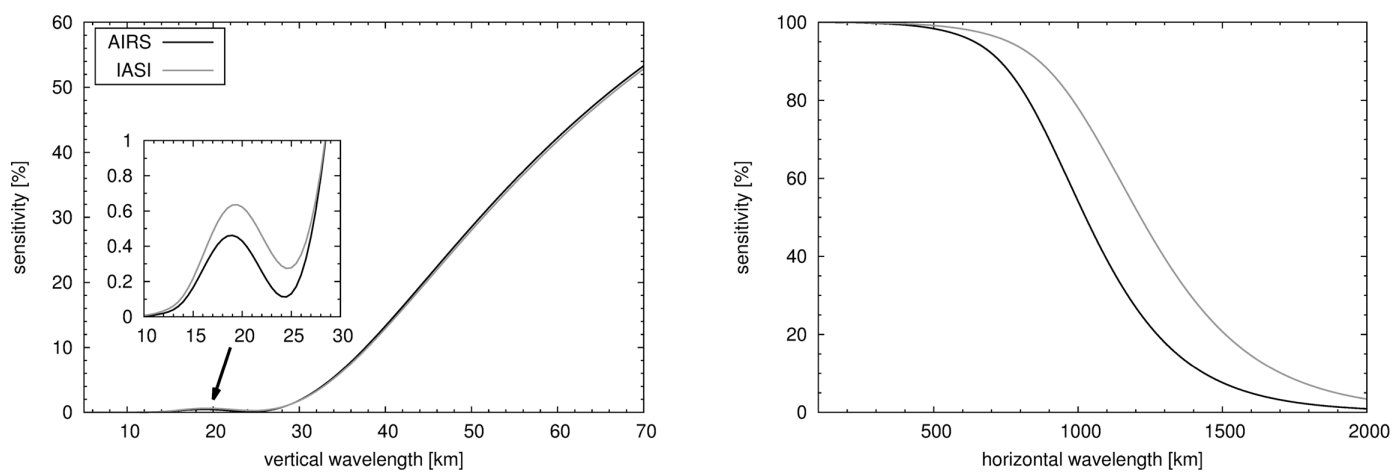

Figure 5. Sensitivity of AIRS and IASI brightness temperature variances to wave perturbations with different vertical wavelengths (left) and horizontal wavelengths (right). Sensitivity to vertical wavelength was calculated with the spectral mean kernel functions shown in Fig. 4. Sensitivity to horizontal wavelength is determined by the detrending procedure. The plot shows the maximum horizontal sensitivity, which is obtained for gravity waves propagating in the across-track direction. Note that the sensitivity to horizontal wavelengths shorter than $100 \mathrm{~km}$ was not analyzed here. In this case the sensitivity is limited by the satellite footprint size (see text for details).

Both the temperature kernel functions and the detrending procedure influence the sensitivity of the AIRS and IASI gravity wave observations. Figure 5 shows the sensitivity of the $4.3 \mu \mathrm{m}$ brightness temperature variances to wave perturbations with different vertical and horizontal wavelengths. The sensitivity to vertical wavelength was determined by convoluting vertical temperature profiles representing wave perturbations with the kernel functions and by calculating the ratio of the variance of the resulting brightness temperature perturbations for all wave phases to their overall maximum. Note that the sensitivity was calculated for waves with a constant amplitude with height. Likewise, sensitivity to horizontal wavelengths was determined by applying the detrending procedure on wave packages in the across-track direction and by calculating the ratio of the variances of the detrended perturbations for different wave phases to their overall maximum. These calculations show that the sensitivity of both instruments first exceeds a level of $1 \%$ for vertical wavelengths larger than $28 \mathrm{~km}$, and that it exceeds the $10 \%$ level at $38 \mathrm{~km}$. A more detailed comparison of the sensitivity curves reveals that IASI is up to 2.5 times more sensitive than AIRS for vertical wavelengths between 10 and $30 \mathrm{~km}$, although it should be noted that sensitivity is generally low in this range for both instruments. For vertical wavelengths larger than $30 \mathrm{~km}$, AIRS and IASI provide the same sensitivity, with relative differences being less than $4 \%$.

Concerning the sensitivity to horizontal wavelengths, IASI was found to be more sensitive than AIRS at wavelengths longer than $600 \mathrm{~km}$. This is due to the broader swath of IASI that allows longer horizontal wavelengths to be seen. The sensitivity drops below $90 \%$ at horizontal wavelengths of $730 \mathrm{~km}$ for AIRS and $870 \mathrm{~km}$ for IASI. It drops below $10 \%$ at $1400 \mathrm{~km}$ for AIRS and $1700 \mathrm{~km}$ for IASI. Note that the calculations shown in Fig. 5 consider only the spatial sampling, but not the spatial resolution of AIRS and IASI. The sensitivity to short horizontal wavelengths is not represented. 

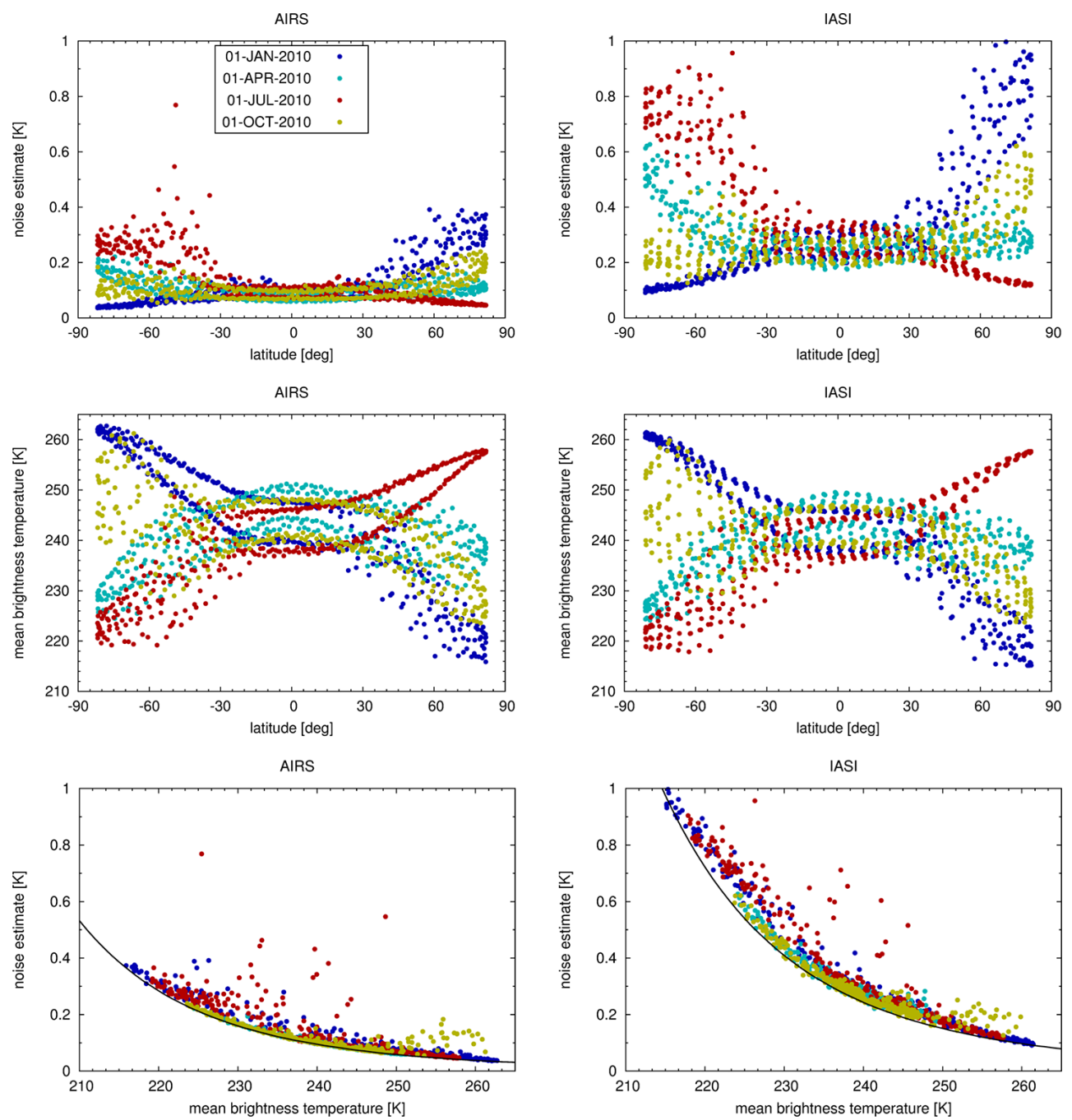

Figure 6. Noise estimates (top) and mean scene temperatures (middle) as a function of latitude as well as correlation plots of noise and scene temperatures (bottom) for AIRS (left) and IASI (right). Individual dots represent mean values for boxes of about $2000 \times 2000 \mathrm{~km}^{2}$. Colors refer to different days of measurement. Black curves show scaling of NEDT with scene temperature.

The sensitivity to short horizontal wavelengths in both AIRS and IASI is limited by the footprint sizes, which are 13.5 and $12 \mathrm{~km}$, respectively. Therefore IASI provides slightly better horizontal resolution, whereas AIRS has finer sampling. IASI can be more sensitive to short-scale wave perturbations, but the coarser and more irregular scan pattern can make it difficult to identify coherent wave patterns. See Fig. 2 for illustration.

Careful characterization of instrument and scene noise is important for gravity wave analyses as noise can contribute significantly to observed brightness temperature variances. An advantage of the $4.3 \mu \mathrm{m}$ waveband analyzed here is that large numbers of channels can be averaged to obtain lownoise data products. Our analysis is based on spectral mean brightness temperatures from 42 channels for AIRS and 154 channels for IASI. However, note that the noise reduction for neither AIRS nor IASI follows a strict $(1 / \sqrt{n})$-scaling law (with $n$ being the number of channels), as both instruments have spectrally correlated noise components. For AIRS correlated noise is introduced as all pixels within a detector module share common circuitry. Correlated noise up to $50 \%$ of the nominal noise was identified in some detector modules (Pagano et al., 2008). For IASI, correlated noise is introduced by the apodization of the radiance spectra.

Instead of using nominal specifications and theoretical considerations regarding noise correlations, we decided to estimate noise directly from the AIRS and IASI measurements. We applied the method of Immerkær (1996), which is a generic technique for noise estimation developed for image analysis. We split the AIRS and IASI measurements along the satellite orbits into individual boxes of $90 \times 90$ and $60 \times 60$ footprints, respectively (about $2000 \times 2000 \mathrm{~km}^{2}$ in both cases). Individual noise estimates for each box were obtained by convoluting the spectral mean $4.3 \mu \mathrm{m}$ brightness 
temperature data with a $3 \times 3$ pixel filter mask to remove image structures. Noise estimates were obtained by calculating the variance of the filtered data. Note that the estimator of Immerkær (1996) perceives thin lines as noise, i.e., plane waves with short wavelengths are potentially misinterpreted as noise. However, as shown below, we applied the analysis separately to hundreds of boxes for both AIRS and IASI in different regions and seasons and found that there are only few outliers of exceptionally high noise that are likely related to that problem. For each of the boxes we also calculated the mean brightness temperature to get an estimate of the scene temperature.

Figure 6 shows our noise estimates for the $4.3 \mu \mathrm{m}$ spectral mean brightness temperature measurements of AIRS and IASI. For both instruments, we found a substantial variation in the noise with latitude and season, with differences of up to a factor of 10. This latitudinal and seasonal variation is due to the dependence of the NEDT on scene temperature. The NEDT decreases with increasing scene temperatures, i.e., it becomes lowest in polar summer (maximum scene temperatures) and highest in polar winter (minimum scene temperatures). Furthermore, Fig. 6 reveals day- and nighttime differences of up to $50 \%$ in noise at low and mid-latitudes. Daytime scene temperatures are up to $10 \mathrm{~K}$ higher than nighttime values as the $\mathrm{CO}_{2}$ molecules experience solar excitation and enter the state of non-local thermodynamic equilibrium (nonLTE) (e.g., de Souza-Machado et al., 2006). Even though there is substantial variability in the individual noise values, scatterplots of noise versus scene temperature reveal compact correlations for both AIRS and IASI, independent of latitude, season, and time of day. To parametrize these compact correlations, we fitted noise scaling curves based on the Planck function $B$ and its inverse $B^{-1}$ to the data,

$\operatorname{NEDT}\left(T_{\mathrm{sc}}\right)=B^{-1}\left[B\left(T_{\mathrm{sc}}\right)+\mathrm{NESR}\right]-T_{\mathrm{sc}}$.

Here we assumed that the NEDT varies with scene temperature $T_{\mathrm{sc}}$ whereas the noise equivalent spectral radiance (NESR) is constant. The NESR was obtained by fitting the $\mathrm{NEDT}_{\text {ref }}$ at a given reference temperature $T_{\text {ref }}$,

$\mathrm{NESR}=B\left(T_{\text {ref }}+\mathrm{NEDT}_{\mathrm{ref}}\right)-B\left(T_{\mathrm{ref}}\right)$.

By fitting to the minimum noise estimates at different scene temperatures, we found noise scaling curves that are defined by $\mathrm{NEDT}_{\text {ref }}=0.059 \mathrm{~K}$ for AIRS and $\mathrm{NEDT}_{\text {ref }}=$ $0.15 \mathrm{~K}$ for IASI, both at $T_{\text {ref }}=250 \mathrm{~K}$ (see Fig. 6). This means the IASI noise at $4.3 \mu \mathrm{m}$ is about 2.4 times larger than the AIRS noise. In other parts of this study we applied the noise scaling curves to determine the noise based on given scene temperatures rather than estimating it individually for each scene. This provides stable results even in scenes with strong wave activity where direct noise estimation from the scene data may fail.

Finally, note that we had to carefully screen the AIRS and IASI data for outliers. In particular in the IASI data we found a few individual footprints with unrealistically large deviations in the $4.3 \mu \mathrm{m}$ brightness temperatures compared to their direct neighbors. Such individual outliers distort the polynomial fit for background estimation and subsequently cause substantial errors in variance estimation. For both AIRS and IASI, we evaluated the operational data quality flags to exclude footprints with degraded data quality. However, for IASI we found that the operational data quality flags do not capture all outliers in the $4.3 \mu \mathrm{m}$ radiances. In some scenes with very low brightness temperatures, which are often related to deep convective clouds in the line of sight, calibration procedures can fail and physically unrealistic spectra are produced. We identified such spectra by means of a correlation test. We calculated the Pearson linear correlation coefficient $\rho$ between the test spectrum and a mid-latitude clearair reference spectrum in the spectral interval from 2320 to $2370 \mathrm{~cm}^{-1}$. If $\rho$ dropped below a latitude-dependent threshold ( 0.0 at the equator, -0.7 at the poles, and linear interpolation in between) the footprint was excluded from further analyses. The combined data quality flags and outlier filters remove about $1.5 \%$ of the IASI footprints. AIRS is much less affected by outliers.

\section{Results}

\subsection{Case study of mountain waves near the Antarctic Peninsula}

We selected a mountain wave event near the Antarctic Peninsula as our first case study for comparison of AIRS and IASI gravity wave observations. The Antarctic Peninsula is the northernmost part of the mainland of Antarctica. It is approximately $1300 \mathrm{~km}$ long and stretches from 75 to $63^{\circ} \mathrm{S}$ and from 76 to $57^{\circ} \mathrm{W}$. The Antarctic Peninsula is a mountain chain, with its highest peak rising to $2800 \mathrm{~m}$. Cape Horn, the southern tip of South America, is about $1000 \mathrm{~km}$ north of the peninsula. A strong circumpolar flow in the wintertime troposphere and stratosphere is a unique feature of Antarctica. The Antarctic Peninsula and Cape Horn create a funneling effect, which directs surface winds into the Drake Passage. Based on this setting, the Antarctic Peninsula becomes a major orographic source for gravity waves. Many observational studies demonstrated that the Antarctic Peninsula is indeed a hotspot of stratospheric gravity wave activity (Wu and Jiang, 2002; Jiang et al., 2006; Baumgaertner and McDonald, 2007; Vincent et al., 2007; Hertzog et al., 2008; S. P. Alexander et al., 2009; Hoffmann et al., 2013). Orographic waves over the Antarctic Peninsula have also been extensively studied by means of mesoscale model simulations (Plougonven et al., 2008; de la Torre et al., 2012; Noel and Pitts, 2012; Orr et al., 2014). Mountain waves generated by the peninsula are of interest not only because of their impact on atmospheric dynamics, but also because they can trigger the formation of polar stratospheric clouds. This 

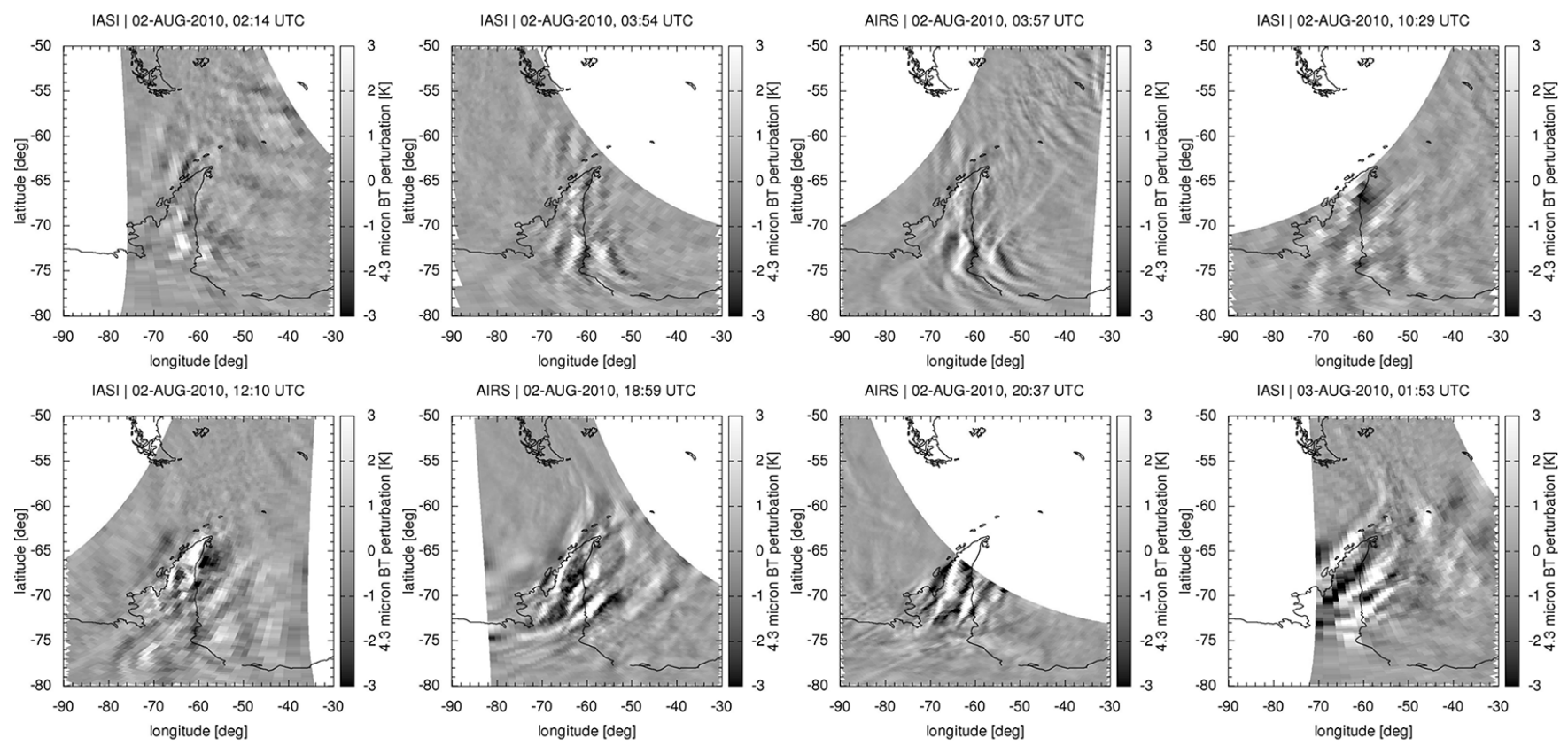

AIRS | 02-AUG-2010, 18:59 UTC

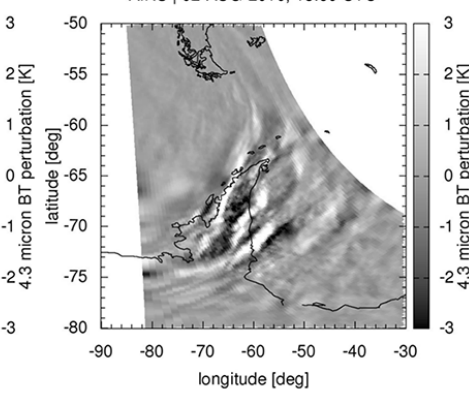

AIRS | 02-AUG-2010, 20:37 UTC

IASI | 03-AUG-2010, 01:53 UTC
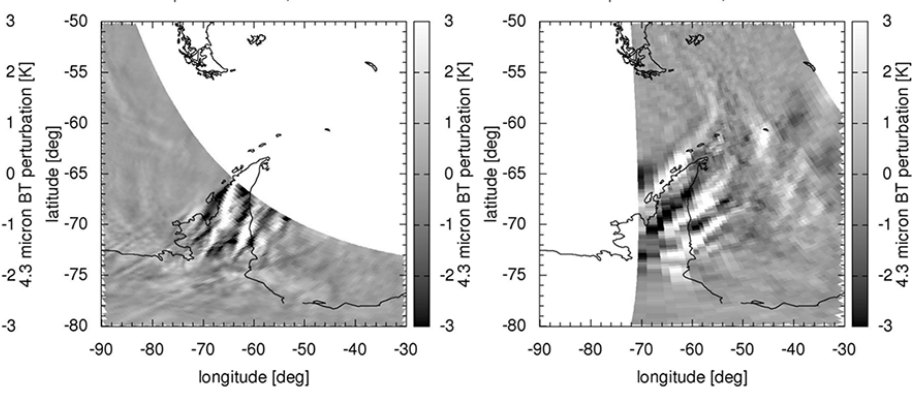

AIRS | 03-AUG-2010, 03:02 UTC

IASI | 03-AUG-2010, 03:33 UTC
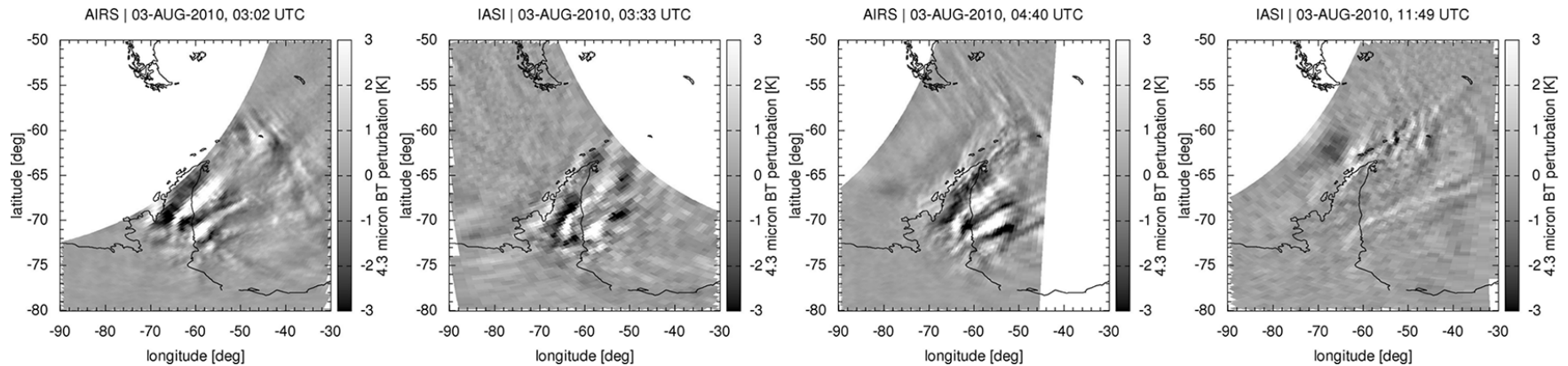

Figure 7. $4.3 \mu \mathrm{m}$ brightness temperature perturbations showing stratospheric temperature perturbations of a mountain wave event at the Antarctic Peninsula on 2-3 August 2010. Plots show observations from selected AIRS and IASI overpasses in temporal order.

is most relevant in early and late winter, when synopticscale temperatures are above formation threshold temperatures (Höpfner et al., 2006; Eckermann et al., 2009; McDonald et al., 2009; Lambert et al., 2012).

Mountain waves over the Antarctic Peninsula often last for a day or longer. They are associated with substantial stratospheric temperature perturbations and with horizontal wavelengths of several hundred kilometers. Mountain waves are stationary, i.e., they remain in a constant position with time. This type of gravity wave is well suited to observation with infrared nadir sounders. Figure 7 shows $4.3 \mu \mathrm{m}$ brightness temperature perturbations for selected AIRS and IASI overpasses of the Antarctic Peninsula during a mountain wave event on 2-3 August 2010. Note that due to the high latitude of the Antarctic Peninsula and also to the broad swath of both instruments, we typically obtain useful observations from four rather than two satellite overpasses per day. The brightness temperature perturbation maps illustrate that both instrument are clearly capable of observing this particular mountain wave event and that together they provide a consistent picture of its temporal development.

There is one particularly remarkable example of coincident AIRS and IASI observations on 2 August 2010, when two overpasses were separated by only a few minutes, occurring at 03:54 and 03:57 UTC. The wave patterns observed by the two instruments show excellent agreement (Fig. 7). We performed a 2-D spectral analysis for the two satellite overpasses using the S-Transform method (Stockwell et al., 1996), and that described by Alexander and Teitelbaum (2007). This approach has the distinct advantage of providing spectrally resolved information on wave amplitude and phase on a variety of local scales. Results are presented in Fig. 8. The patterns found in the wave amplitudes provided by the spectral analysis clearly coincide with the wave patterns in the observed brightness temperature perturbations. The maximum wave amplitudes are up to $3.9 \mathrm{~K}$ for IASI and $5.2 \mathrm{~K}$ for AIRS. Considering only data points with wave amplitudes larger than $1 \mathrm{~K}$, the amplitude-weighted mean horizontal wavelengths are $170 \mathrm{~km}$ for IASI and $130 \mathrm{~km}$ for AIRS. 

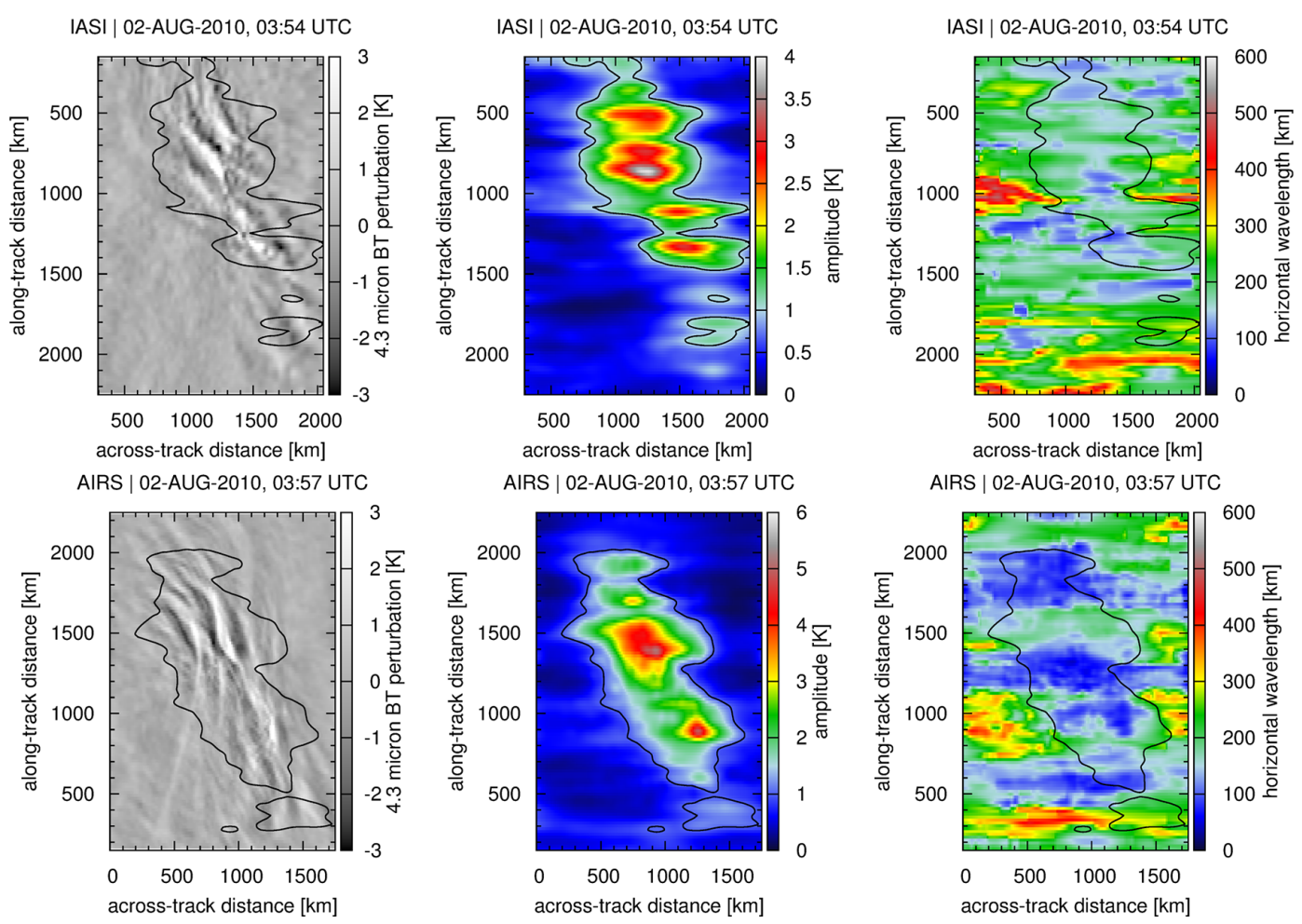

Figure 8. Spectral analyses for two satellite overpasses of IASI (top) and AIRS (bottom) during the mountain wave event shown in Fig. 7. Data are shown on the along-track and across-track measurement grid, with a descending orbit for IASI and an ascending orbit for AIRS. Black contour lines indicate areas with wave amplitudes larger than $1 \mathrm{~K}$.

These results from the spectral analyses show that both the AIRS and IASI measurements are very similar. The remaining differences are most likely related to the fact that AIRS has better horizontal sampling than IASI, which allows for smaller horizontal wavelengths to be resolved in the spectral analysis.

\subsection{Case study of orographic waves near the Kerguelen Islands and Heard Island}

For our second case study, we present orographic waves near Kerguelen Islands $\left(49^{\circ} \mathrm{S}, 70^{\circ} \mathrm{E}\right)$ and Heard Island $\left(53^{\circ} \mathrm{S}\right.$, $74^{\circ} \mathrm{E}$ ). Gibbs (1945) provides a geographical report on these remote islands in the southern Indian Ocean. The Kerguelen Islands, also known as the Desolation Islands, are more than $3300 \mathrm{~km}$ away from the nearest populated location. The main island, Grande Terre, extends $150 \mathrm{~km}$ east to west and $120 \mathrm{~km}$ north to south and is surrounded by numerous smaller islands. The highest point on Grand Terre is Mont Ross $(1850 \mathrm{~m})$. Heard Island is located about $470 \mathrm{~km}$ southeast of the Kerguelen Islands. Heard Island has an area of $370 \mathrm{~km}^{2}$. Its highest summit is Mawson Peak $(2745 \mathrm{~m})$, an active volcano. The climate of the Kerguelen Islands and Heard Island is subpolar oceanic, tempered by a maritime setting. The islands are located in the "Roaring Forties" and
"Furious Fifties". Their west coasts receive continuous winds of $5-10 \mathrm{~m} \mathrm{~s}^{-1}$; wind gusts of $40-50 \mathrm{~m} \mathrm{~s}^{-1}$ are common. ${ }^{1}$

Satellite observations of orographic gravity waves generated by flow over small islands in the southern oceans have been discussed in several studies (Wu et al., 2006; Alexander et al., 2009; Alexander and Grimsdell, 2013; Hoffmann et al., 2013). In particular, Alexander and Grimsdell (2013) examined the occurrence frequencies of these waves in the stratosphere above 14 islands based on 2 years of AIRS observations. Their study showed that waves commonly occur in the May to September season, though not every day. Differing seasonal variations became evident at different islands, but the seasonal variations were closely related to latitude and prevailing wind patterns. Alexander and Grimsdell (2013) found that stratospheric winds have a first-order limiting effect on satellite observations of the island mountain waves. Surface wind direction and island orographic relief have a secondary influence on the wave occurrence frequencies. Estimates of momentum flux for these wave events demonstrate their importance to the general circulation of the Southern Hemisphere.

In this case study, we focus on observations of orographic waves near the Kerguelen Islands and Heard Island on 23-

\footnotetext{
${ }^{1}$ See http://www.heardisland.aq/about/climate-and-weather (last access: 6 August 2014).
} 

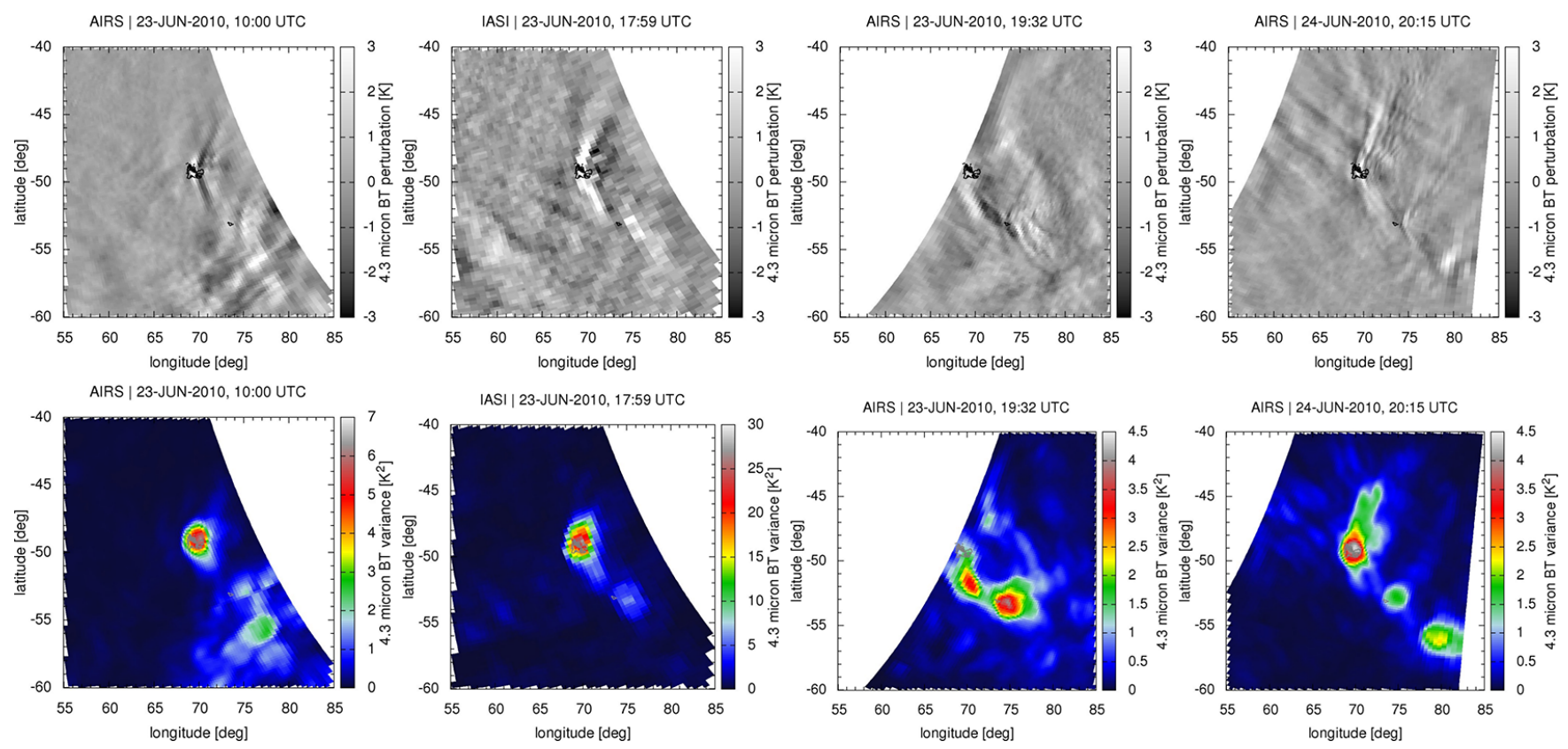

Figure 9. $4.3 \mu \mathrm{m}$ brightness temperature perturbations (top) and local variances (bottom) related to orographic waves near the Kerguelen Islands and Heard Island on 23-24 June 2010. The local variances are calculated based on the perturbations of footprints within circles with $100 \mathrm{~km}$ radius. Note that fixed color bar ranges are used for perturbations, whereas variable ranges are used for the variances.

24 June 2010. Figure 9 shows brightness temperature perturbation maps of selected AIRS and IASI overpasses. The maps illustrate that both AIRS and IASI are clearly capable of observing this type of wave event. However, note that these observations are more challenging for IASI, compared to mountain wave events at the Antarctic Peninsula, because the horizontal wavelengths are usually much shorter. To illustrate this, an AIRS map for another wave event on 24 June 2010, 20:15 UTC is given in Fig. 9. This map reveals orographic waves with horizontal wavelengths as short as $70 \mathrm{~km}$ northeast of the Kerguelen Islands. Such waves would be difficult to observe and identify as a coherent wave pattern with IASI due to its fairly coarse and irregular sampling pattern.

Figure 9 also shows maps of local variances that measure the variance within circles of $100 \mathrm{~km}$ radius (see Hoffmann and Alexander, 2010; Hoffmann et al., 2013). Both instruments recorded strong gravity wave activity in the stratosphere, with maximum local variances up to $28 \mathrm{~K}^{2}$ for IASI and $6 \mathrm{~K}^{2}$ for AIRS at the Kerguelen Islands and $7 \mathrm{~K}^{2}$ for IASI and $4 \mathrm{~K}^{2}$ for AIRS at Heard Island. We think that the larger variances of IASI are partly due to the better horizontal resolution of IASI (i.e., its smaller footprint size), which makes the instrument more sensitive to large wave amplitudes from short-scale waves. We also analyzed this particular event for visibility effects, i.e., changes in sensitivity due to wavelength changes along the line-of-sight depending on the scan angle. However, we found that this does not play a role in this case study. The combined AIRS and IASI data indicate that the island mountain waves are rather variable in time. In many situations we found strong wave events only in single AIRS or IASI overpasses, but not in subsequent satellite overpasses.

\subsection{Case study of convective waves during the North American thunderstorm season}

The third case study we present is of a convective wave event during the thunderstorm season of the North American Great Plains. The thunderstorm season usually begins in late April and continues until early September. The meteorological situation is characterized by a southerly low-level jet shifting north, i.e., warm and moist air from the Gulf of Mexico can invade inner continental regions. The moist air feeds thunderstorms, which develop in advance of Pacific cold fronts. The thunderstorms cluster in swaths, oriented southwest to northeast, and move towards the northeast ahead of the fronts. Deep convection related to thunderstorms is an important source for gravity waves. Convective waves in the summer mid- and high latitudes may play a leading role in driving the stratospheric Brewer-Dobson circulation in the summer hemisphere (Alexander and Rosenlof, 1996). Hoffmann and Alexander (2010) analyzed the occurrence frequency of convective waves during the North American thunderstorm season based on AIRS data. This shows that more than $95 \%$ of the observed gravity waves in a core region over the North American Great Plains ( 36 to $46^{\circ} \mathrm{N}, 88$ to $98^{\circ} \mathrm{W}$ ) are associated with deep convection. The occurrence frequency of these convective waves varies with time of day. Stronger ac- 

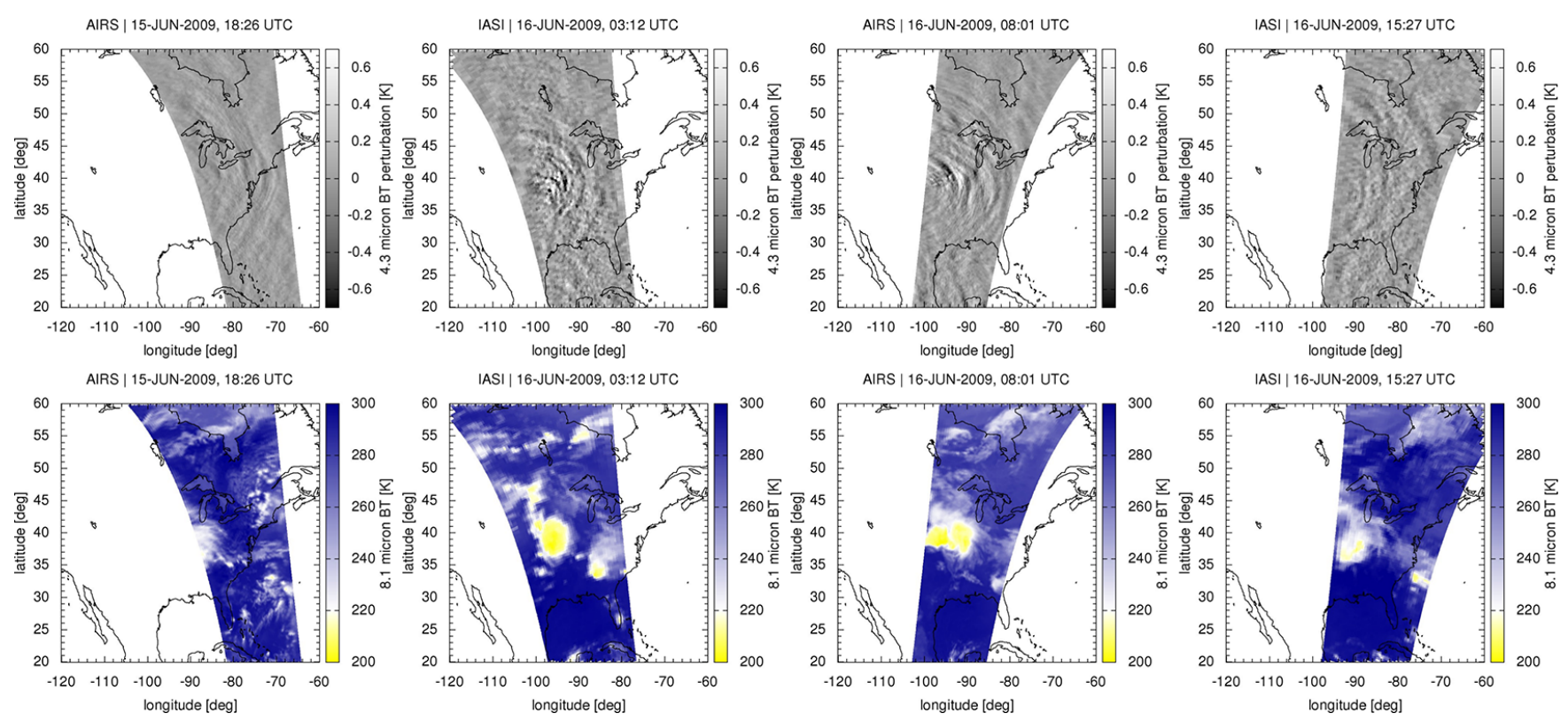

Figure 10. $4.3 \mu \mathrm{m}$ brightness temperature perturbations (top) from a convective wave event over the North American Great Plains on 1516 June 2009. Note that perturbations are much smaller compared with Figs. 7 and 9. The $8.1 \mu$ m brightness temperature maps (bottom) show cold cloud surfaces $(<220 \mathrm{~K})$ related to mesoscale convective systems.

tivity is observed for the descending orbits of AIRS, which are measured at a local time of 01:30 a.m. The different local times of the AIRS and IASI orbits (Fig. 1) present the opportunity to study the temporal development of these convective waves in more detail.

In this case study, we focus on a convective wave event on 16 June 2009 (Fig. 10). We present four satellite overpasses within a time period of $21 \mathrm{~h}$. Convective waves are observed during two overpasses, at 03:12 UTC by IASI and at 08:01 UTC by AIRS. The convective waves can be identified in the perturbations maps based on their semi-circular shape. Note that the observed wave fronts preferably propagate eastward, corresponding to strong easterly background winds that foster the propagation of waves with long vertical wavelengths in that direction. Those long vertical wavelengths are best visible to AIRS and IASI (Sect. 2.2). Figure 10 also shows maps of $8.1 \mu \mathrm{m}\left(1231 \mathrm{~cm}^{-1}\right)$ brightness temperatures. These maps allow identification of deep convection based on low brightness temperatures (e.g., Hoffmann and Alexander, 2010; Aumann et al., 2011), which are related to optically thick, cold surfaces of clouds at high altitude. The $8.1 \mu \mathrm{m}$ maps show a mesoscale convective system near the center of the semi-circular wave patterns $\left(40^{\circ} \mathrm{N}\right.$, $95^{\circ} \mathrm{W}$ ), indicating that the waves are indeed convectively driven and that this convective system is the source.

Note that this case study presents one of the most distinct cases of coincident convective wave observations with AIRS and IASI that we could identify during the time period of 2008 to 2012. Convective waves are very difficult for both AIRS and IASI to identify because these waves usually have much weaker amplitudes than orographic waves and they are much more variable in time due to the variability of the convective sources. Convective wave observations are usually noise-limited, in particular for IASI. The IASI observations sometimes reveal fluctuating strong brightness temperature perturbations close to the center of the convective waves, which may be related to its better horizontal resolution. AIRS shows smaller perturbations, but the wave patterns are more coherent due to the better horizontal sampling.

\subsection{Temporal patterns of stratospheric gravity wave activity}

In this section we describe statistical analyses of the stratospheric gravity wave variances from AIRS and IASI. The analyses span the time period of January 2008 to December 2012, which has nearly complete coverage by both AIRS and IASI. During that time period, AIRS measured about $5.3 \times 10^{9}$ radiance spectra and IASI about $2.3 \times 10^{9}$. Statistical sampling errors can be neglected in most cases due to the large number of measurements. An exception is at high latitudes (beyond $\pm 85^{\circ}$ ), where the number of measurements decreases rapidly. This region is excluded from our analysis. As gravity wave activity varies with local time, the analyses are carried out separately for the ascending orbits of AIRS and descending orbits of IASI (daytime data) as well as the descending orbits of AIRS and ascending orbits of IASI (nighttime data). To illustrate our analyses, Fig. 11 shows time series of the daily mean, zonal mean $4.3 \mu \mathrm{m}$ brightness temperature background levels, noise estimates, and gravity 
wave variances for $1^{\circ}$ latitude bins from the IASI nighttime data.

The IASI background shows that the lowest temperatures occur during the polar winter, and the highest temperatures occur during the polar summer. At low latitudes (below $\pm 25^{\circ}$ ), the temperature variations were small (up to $\pm 5 \mathrm{~K}$ ), but the variability increased towards polar latitudes (up to $\pm 30 \mathrm{~K})$. A remarkable feature of the time series is the stratospheric sudden warmings (e.g., Charlton and Polvani, 2007; Ayarzagüena et al., 2011), which increase background temperatures by up to $40 \mathrm{~K}$ in the polar regions and decrease them by $5-10 \mathrm{~K}$ at low and mid-latitudes. Comparing dayand nighttime data (not shown), we found that the daytime background temperatures were biased high by up to $10 \mathrm{~K}$ within $\pm 60^{\circ}$ latitude. The bias diminishes towards the poles. It is attributed to the non-LTE effect (Sect. 2.2). Note that the non-LTE bias of the daytime background temperatures is rather constant in space and time and is effectively removed by the detrending procedure. Comparing AIRS and IASI (not shown), we found excellent agreement in the background temperatures with differences being less than $\pm 2 \mathrm{~K}$ at all latitudes at day- and nighttime.

Figures 11 and 12 show time series of noise variances for AIRS and IASI, which we calculated from the $4.3 \mu \mathrm{m}$ background temperatures and the noise scaling functions presented in Sect. 2.2. Depending on latitude, season, and time of day, the noise variances can fluctuate by 2-3 orders of magnitude, i.e., from 0.00076 to $0.60 \mathrm{~K}^{2}$ for AIRS and from 0.0046 to $2.8 \mathrm{~K}^{2}$ for IASI. Being anti-correlated with background temperatures, the lowest noise is found in the polar summer and the highest noise is found in the polar winter. Day- and nighttime differences in background temperatures due to non-LTE are found in the noise as well, with nighttime noise variances typically 2-5 times larger than daytime noise variances at low and mid-latitudes. Comparing AIRS and IASI, it is found that IASI noise variances are typically 3-6 times larger than AIRS noise variances. Individual gravity wave events may yield local variances of $10 \mathrm{~K}^{2}$ or more (e.g., Sect. 3.2). Zonally or seasonally averaged gravity wave variances are typically lower (on the order of $1 \mathrm{~K}^{2}$, see below). The large variation of the $4.3 \mu \mathrm{m}$ noise with latitude, season, and time of day found here demonstrates that a careful characterization and noise correction in statistical analyses of gravity wave variances is mandatory.

Figures 11 and 12 also show time series of $4.3 \mu \mathrm{m}$ brightness temperature variances due to gravity wave activity. Both AIRS and IASI show similar seasonal cycles in gravity wave activity, including a strong cycle with maxima in winter midand high latitudes and a weaker cycle with maxima in summer low latitudes. We found daily maxima of the zonal mean gravity wave variances up to $2 \mathrm{~K}^{2}$ at mid- and high latitudes in the winter hemispheres. In contrast, the daily maxima of the summer cycle are typically 20-30 times smaller than the maxima of the winter cycle. Note that the zonal winds in the middle stratosphere have a strong influence on the AIRS and IASI gravity wave observations. Strong winds foster the propagation of gravity waves with long vertical wavelengths, which are best visible to the nadir sounders (Sect. 2.2). Figure 11 shows a time series of zonal mean zonal winds at $6.8 \mathrm{hPa}$ (about $35 \mathrm{~km}$, at the AIRS and IASI observation level) from the European Centre for Medium-Range Weather Forecast ERA-Interim reanalysis (Dee et al., 2011). The time series of the gravity wave variances and the zonal winds are clearly correlated, with the winter cycle maxima in wave activity being associated with strong westerlies and the summer cycle maxima being associated with prevailing easterlies.

Although the temporal patterns of gravity wave activity from AIRS and IASI are in agreement, Fig. 12 reveals some differences. The IASI variances are systematically larger than the AIRS variances, with the largest differences being found in the winter cycle maxima (up to $1 \mathrm{~K}^{2}$ ). In contrast, at equatorial latitudes the AIRS and IASI variances agree well, with differences below $\pm 0.015 \mathrm{~K}^{2}$. As the observed wave activity at equatorial latitudes is close to zero, the small differences found here relate to the accuracy of the AIRS and IASI noise corrections and indicate that these corrections were carried out properly. Note also that the noise corrections remove the day- and nighttime differences. To quantify the remaining differences between AIRS and IASI, we determined the linear scaling factor between the gravity wave variances,

$c_{\mathrm{ai}}=1.454 \pm 0.042$.

This is a combined value for day- and nighttime data. A separate analysis for day- and nighttime yields similar scaling factors (with differences of less than $5 \%$ ). Figure 12 also reveals systematic differences between day- and nighttime data, with nighttime variances being larger than daytime variances. The linear scaling factor between the gravity wave variances is

$c_{\mathrm{dn}}=1.315 \pm 0.062$.

This is a combined value based on AIRS data, scaled to IASI levels by multiplying with $c_{\mathrm{ai}}$, and unaltered IASI data. A separate analysis for AIRS and IASI again yields similar scaling factors (with differences of less than $5 \%$ ).

\subsection{Spatial patterns of stratospheric gravity wave activity}

In this section we discuss the spatial distributions of the AIRS and IASI gravity wave variances in different seasons. Figures 13 and 14 show 5-year averages (2008-2012) of monthly mean variances in January and July, respectively. The variances were calculated on a $1^{\circ} \times 1^{\circ}$ horizontal grid. We scaled the AIRS data with the global factor $c_{\mathrm{ai}}$ and the daytime data with the global factor $c_{\mathrm{dn}}$ to compensate for some of the systematic differences discussed in Sect. 3.4. The comparison of the scaled data shows good agreement in many cases. The remaining differences are mostly below 

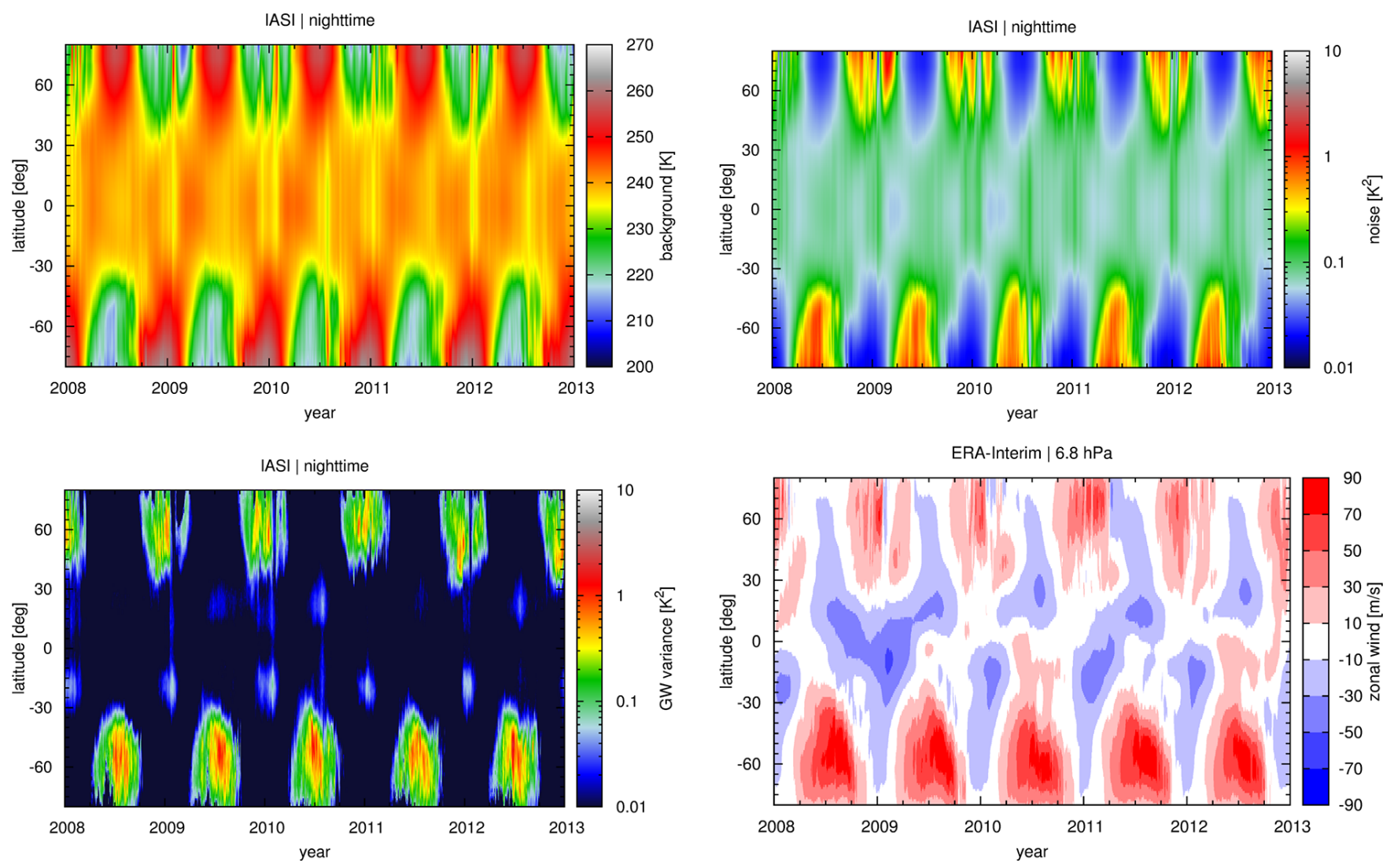

Figure 11. Time series of $4.3 \mu \mathrm{m}$ brightness temperature background levels (top, left), noise estimates (top, right), and gravity wave variances (bottom, left) from IASI nighttime observations. Time series of ERA-Interim zonal mean zonal winds at $6.8 \mathrm{hPa}$ (bottom, right).

$\pm 0.2 \mathrm{~K}^{2}$. Larger differences are found only in a few locations with exceptionally strong gravity wave activity. In these cases the global correction of the scaling approach may not be suited for the specific local gravity wave spectra. Note that there is some statistical uncertainty due to the limited length of the time series, in particular in the cases where the variances are mainly determined by a few, exceptionally strong events. However, the remaining differences are certainly linked to local time variation of the gravity wave sources as well.

The monthly maps presented in Figs. 13 and 14 reveal distinct features of stratospheric gravity wave activity. The most obvious feature is the bands of strong activity at mid- and high latitudes in the winter hemispheres, which are confined by bands of strong westerly winds (exceeding $20-40 \mathrm{~m} \mathrm{~s}^{-1}$ ). In the Southern Hemisphere, wave activity is more zonally symmetric. A notable exception is found near the Andes and the Antarctic Peninsula, where wave activity is up to 10 times larger than the zonal mean. Another exception is found over the southern Atlantic and Indian Ocean $\left(50-70^{\circ} \mathrm{S}, 0\right.$ $120^{\circ} \mathrm{E}$ ), which correlates with even stronger stratospheric winds $\left(>80 \mathrm{~m} \mathrm{~s}^{-1}\right)$. In the Northern Hemisphere, the observed distribution of gravity wave activity is zonally asymmetric due to the asymmetry in the orography and back- ground winds. The largest wave activity is observed over the Atlantic Ocean and Europe. In the summer hemispheres, we observe weaker local maxima at low and mid-latitudes that coincide with regions of convective activity and that are confined by easterly winds exceeding $-20 \mathrm{~m} \mathrm{~s}^{-1}$. This includes the North American Great Plains and southeast Asia in boreal summer (July) and central South America, southern Africa, and northern Australia in austral summer (January). Due to the high horizontal resolution, AIRS and IASI are both well capable of resolving small-scale hotspots of stratospheric gravity wave activity, which are discussed in detail by Hoffmann et al. (2013).

\section{Discussion and conclusions}

In this study we performed an intercomparison of $4.3 \mu \mathrm{m}$ brightness temperature measurements of AIRS and IASI to assess how stratospheric gravity wave observations of both instruments relate to each other. The analyses were based on spectral mean radiances rather than on spectrally resolved data. The main advantages of spectral averaging are that it reduces noise and that it makes the measurements comparable in terms of vertical coverage. A disadvantage is that 

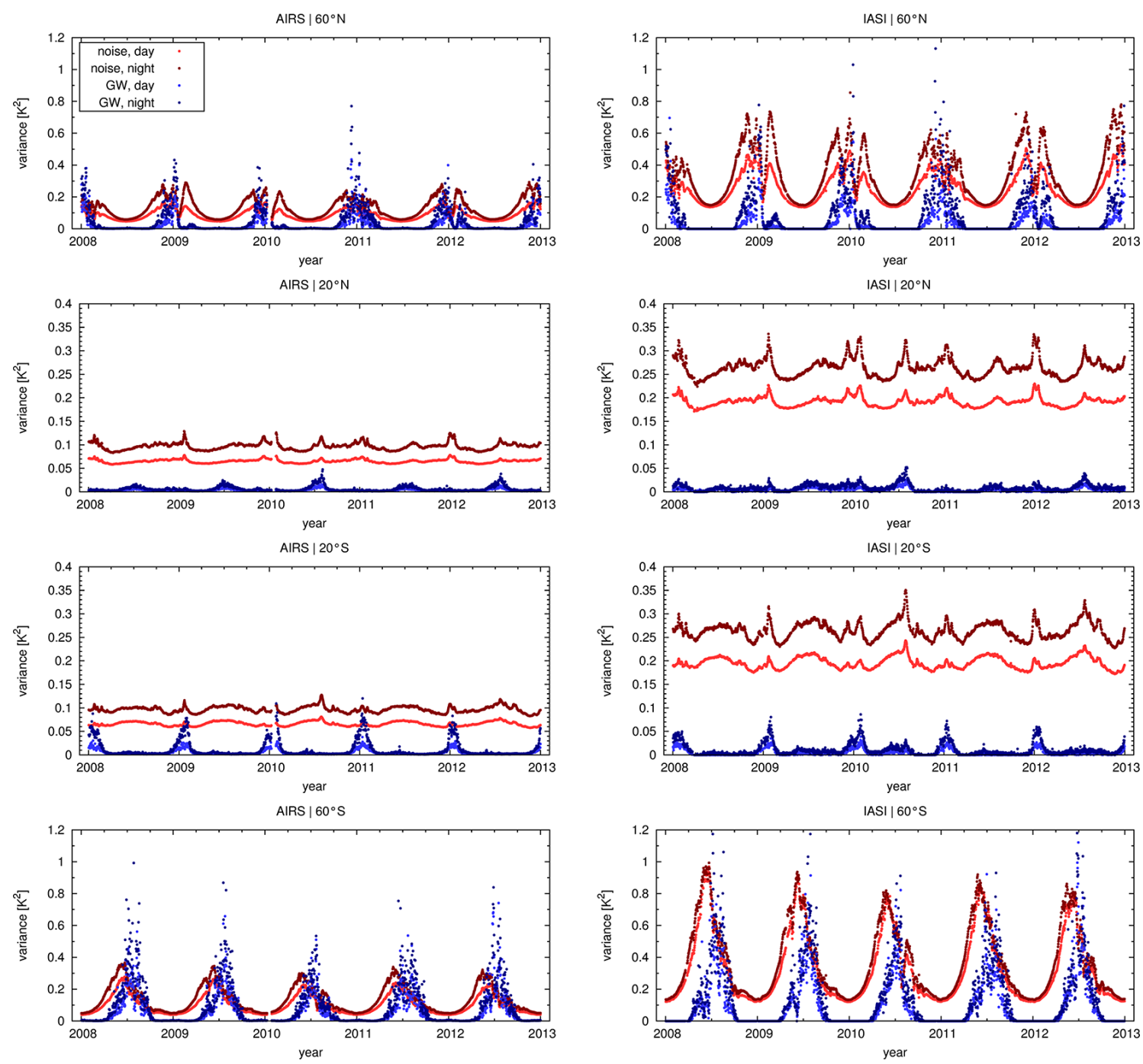

Figure 12. Time series of $4.3 \mu \mathrm{m}$ brightness temperature variances due to gravity waves and noise estimates for AIRS (left) and IASI (right) at different latitudes (see plot titles). Note that the range of variances shown here differs between the lower and higher latitudes.

altitude information gets lost, in particular for IASI with its high spectral resolution. In summary, we found that AIRS and IASI are both well capable of observing stratospheric gravity waves with long vertical and short horizontal wavelengths. These waves are believed to be rather important as they can potentially carry large momentum flux and excite significant wave drag. AIRS and IASI observe these waves most frequently at mid- and high latitudes in winter, where they are related to orographic sources and the polar jet, and at low and mid-latitudes in summer, where convective sources play an important role. Stratospheric gravity wave activity was mostly observed in regions with background zonal winds exceeding wind speeds of $\pm 20 \mathrm{~m} \mathrm{~s}^{-1}$. Strong winds foster the propagation of gravity waves with long vertical wavelengths, which are best visible to the nadir sounders.

For gravity wave research, it is most promising that AIRS and IASI measure at different local times. Combining obser- vations from both instruments provides a clearer picture of the temporal development of individual gravity wave events than a single instrument alone. The case study for the Antarctic Peninsula showed a mountain wave event that lasted for a period of $48 \mathrm{~h}$. During that time the Antarctic Peninsula was covered by 16 satellite overpasses. On one occasion the AIRS and IASI measurements were separated only by a few minutes' time and we found that the observed wave patterns are in excellent agreement. Furthermore, we also identified cases of orographic waves near isolated islands and convective waves near a mesoscale convective system where AIRS and IASI provided coincident measurements. The case studies revealed distinct advantages of AIRS compared to IASI with respect to the horizontal sampling and resolution of the observations. The finer horizontal sampling of AIRS allows one to resolve coherent wave patterns even in the case of short-scale waves. In contrast, IASI has better spatial reso- 

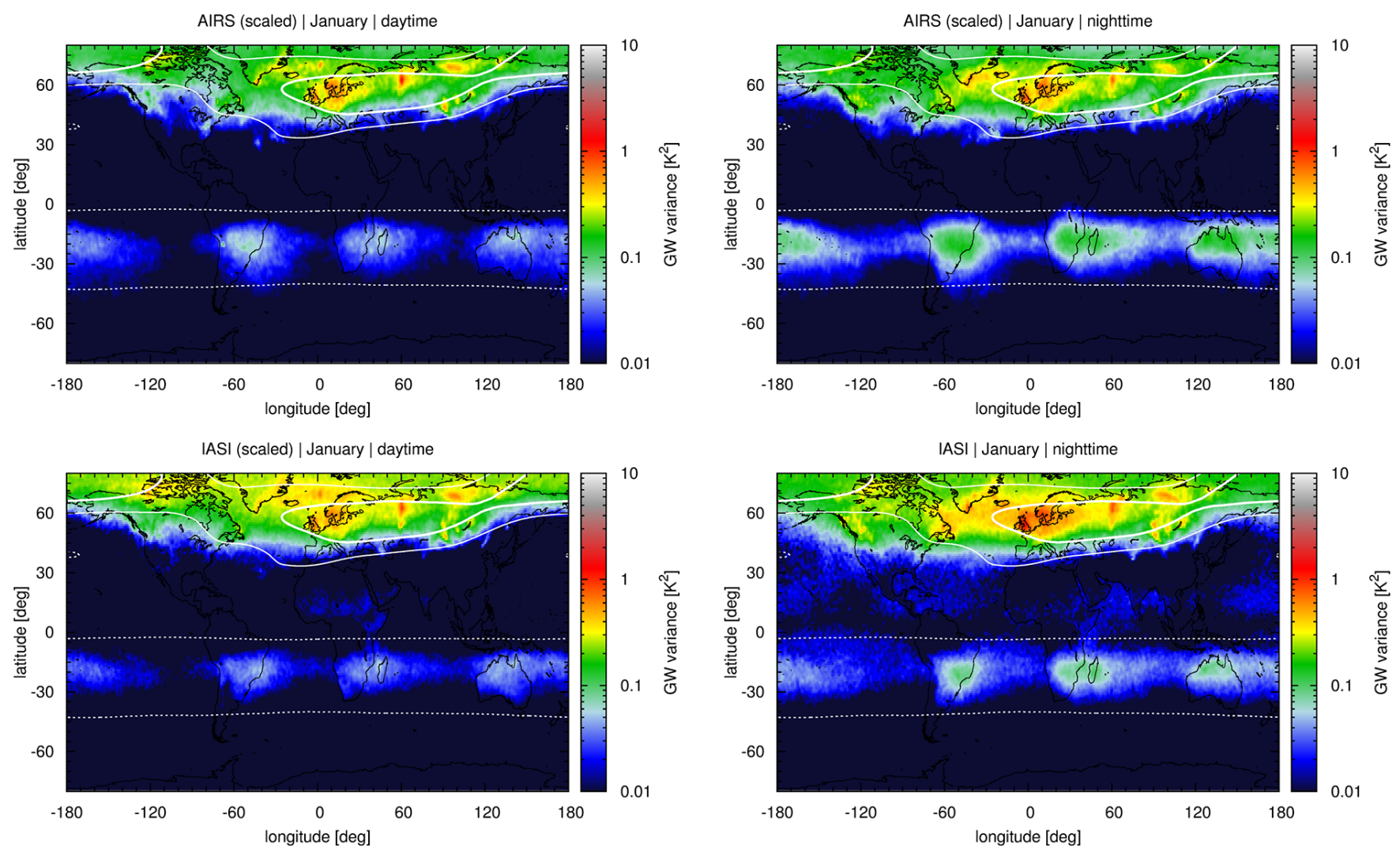

Figure 13. Climatological maps of $4.3 \mu \mathrm{m}$ brightness temperature variances due to gravity waves in January for AIRS (top) and IASI (bottom) at daytime (left) and nighttime (right). Shown are mean variances based on the years 2008 to 2012. Data have been scaled by the factors $c_{\mathrm{ai}}$ and $c_{\mathrm{dn}}$ to better compare regional features. White contour lines show zonal winds of $-20 \mathrm{~m} \mathrm{~s}^{-1}$ (thin, dotted), $20 \mathrm{~m} \mathrm{~s}{ }^{-1}$ (thin, solid), and $40 \mathrm{~m} \mathrm{~s}^{-1}$ (thick, solid) at $6.8 \mathrm{hPa}$ from ERA-Interim.

lution than AIRS and is more sensitive to large amplitudes of short-scale waves. The observed wave patterns may not be as coherent as for AIRS, though, due to the coarser and more irregular sampling pattern of IASI. Another advantage of IASI is its broader swath that reduces data gaps between subsequent measurement tracks and improves global coverage.

A statistical comparison based on 5-year time series (2008-2012) revealed that the IASI gravity wave variances are on average $45 \%$ larger than for AIRS. There are several possible reasons for these differences: (i) IASI can be up to 2.5 times more sensitive for vertical wavelengths from 10 to $30 \mathrm{~km}$. Although the response in brightness temperature variances is quite low at these wavelengths (Fig. 5), this is a common wavelength range for mountain waves in the stratosphere. So this difference in sensitivity may be important. (ii) The wider swath width of IASI gives sensitivity to longer horizontal wavelength (Fig. 5) that can contribute to larger variances. (iii) The smaller footprint of IASI $(12 \mathrm{~km}$ diameter at nadir versus $13.5 \mathrm{~km}$ for AIRS) gives sensitivity to short horizontal wavelength waves near this limit that could contribute to larger variances, even though the coarser sampling of IASI does not permit resolution of such short waves. (iv) IASI noise variances are up to 6 times larger than for AIRS, hence imperfect noise characterization could still be influencing these results. A specific problem with noise characterization is related to assigning the appropriate scene temperature for each footprint, in particular in scenes with strong variations in radiance. In addition, we also analyzed day- and nighttime differences and found that gravity wave variances are about $30 \%$ larger at nighttime for both, AIRS and IASI. Part of this difference is due to local time variation of gravity wave sources, such as convection. Part of the difference may also be due to the different sensitivities of AIRS and IASI to gravity waves propagating in the alongor across-track direction. In particular, this may play a role if the gravity waves are observed from either ascending or descending sections of the satellite orbits.

Despite the systematic differences, the seasonal and latitudinal distributions of stratospheric gravity wave activity found here agree well with other climatologies (e.g., Jiang et al., 2005; Preusse et al., 2009a; Gong et al., 2012; Hoffmann et al., 2013). Our analysis reproduces major features like orography- and jet-related wintertime maxima at midand high latitudes, low- and mid-latitude summertime maxima from convective sources, and the most prominent lo- 

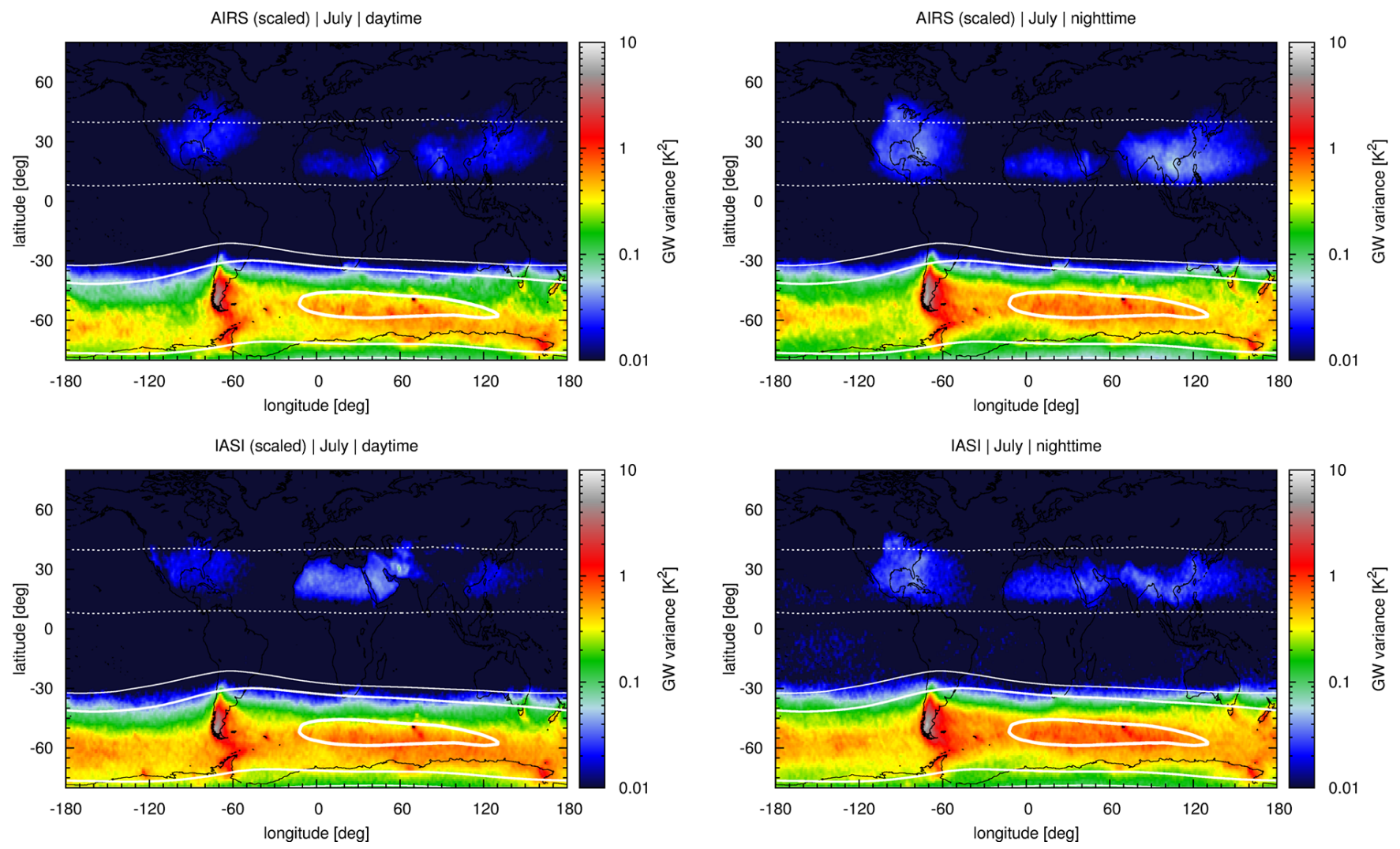

Figure 14. Same as Fig. 13, but for July. Another thick contour line was added, showing zonal winds of $80 \mathrm{~m} \mathrm{~s}^{-1}$ in the Southern Hemisphere.

cal hotspots of stratospheric gravity waves. We also found good quantitative agreement of the gravity wave variances with the climatology of Gong et al. (2012), which is based on $15 \mu \mathrm{m}$ radiance measurements from AIRS. In their study, Gong et al. (2012, Fig. 4) found maximum zonal mean variances near $3 \mathrm{hPa}$ (about $40 \mathrm{~km}$ ) up to $0.3 \mathrm{~K}^{2}$ at 50 to $60^{\circ} \mathrm{N}$ and up to $0.1 \mathrm{~K}^{2}$ at 10 to $20^{\circ} \mathrm{S}$ in January 2005 . They found even larger maxima in Southern Hemisphere winter (up to $0.5 \mathrm{~K}^{2}$, July 2005), which can also be found in our record.

We recognized that noise is an important contributor to the observed $4.3 \mu \mathrm{m}$ brightness temperature variances. Noise needs to be characterized carefully and subtracted from the variances of the detrended measurements to isolate the gravity wave signals. We applied a technique developed for image analysis to estimate the noise directly from the AIRS and IASI measurements. Our approach takes spectrally correlated noise components into account, which is rather important as we average data from large numbers of channels. For both instruments, we found that the $4.3 \mu \mathrm{m}$ noise variances vary substantially with scene temperature, i.e., by 2 to 3 orders of magnitude. The IASI noise at $4.3 \mu \mathrm{m}$ is about 2.4 times larger than the AIRS noise. Noise poses a limiting factor for gravity wave observations in the cases with low amplitudes, in particular for convective waves.
Previous studies on AIRS may not have taken the large variability of noise with scene temperature fully into account. For instance, in the study of Gong et al. (2012), it was assumed that noise does not vary with location and time. This may have been appropriate in their study because they analyzed $15 \mu \mathrm{m}$ rather than $4.3 \mu \mathrm{m}$ brightness temperatures, with weaker dependence of the noise on the scene temperature. Gong et al. (2012) estimated noise directly from the measurements and found that minima occur at summer hemisphere high latitudes, which is confirmed by our results. Wu and Waters (1996) and Wu and Eckermann (2008) point out that the minimum detectable gravity wave variance is directly related to the noise variance. As a consequence, the minimum detection level for the $4.3 \mu \mathrm{m}$ observations varies substantially with the scene temperature. The study of Hoffmann et al. (2013) presented a detection algorithm for stratospheric gravity waves that implicitly considered the large noise variation at $4.3 \mu \mathrm{m}$. That study used variance thresholds for detection that vary with latitude, season, and time of day.

While AIRS has been successfully used in many studies on gravity wave research, IASI data are applied here for the first time for that purpose. Our study indicates that gravity wave observations from different hyperspectral infrared nadir sounders such as AIRS and IASI can be directly related to each other if instrument-specific characteristics such 
as different noise levels as well as spatial sampling and resolution are carefully considered. This is promising concerning future work with IASI because of its long-term perspective with three MetOp satellites being launched in the time period of 2006 to 2018. The Cross-track Infrared Sounder (CrIS) (Bloom, 2001; Smith Sr. et al., 2009) onboard NASA's Suomi NPP satellite platform, launched in October 2011, offers another opportunity for gravity wave research based on combined nadir sounder observations.

Acknowledgements. AIRS data products are distributed by the NASA Goddard Earth Sciences Data Information and Services Center (GES DISC). IASI data products were obtained from the British Atmospheric Data Centre (BADC). ERA-Interim data are provided by the European Centre for Medium-Range Weather Forecasts (ECMWF). Support for this work was provided by the NASA program, The Science of Terra and Aqua, contract NNH11CD34C. C. Clerbaux is grateful to the Centre national d'études spatiales (CNES) and to the National Center for Atmospheric Research (NCAR) for financial support.

The service charges for this open access publication

have been covered by a Research Centre of the

Helmholtz Association.

Edited by: S. Kirkwood

\section{References}

Alexander, M. J. and Barnet, C. D.: Using satellite observations to constrain gravity wave parameterizations for global models, J. Atmos. Sci., 64, 1652-1665, 2007.

Alexander, M. J. and Grimsdell, A. W.: Seasonal cycle of orographic gravity wave occurrence above small islands in the Southern Hemisphere: Implications for effects on the general circulation, J. Geophys. Res., 118, 11589-11599, 2013.

Alexander, M. J. and Pfister, L.: Gravity wave momentum flux in the lower stratosphere over convection, Geophys. Res. Lett., 22, 2029-2032, 1995.

Alexander, M. J. and Rosenlof, K. H.: Nonstationary gravity wave forcing of the stratospheric zonal mean wind, J. Geophys. Res., 101, 23465-23474, 1996.

Alexander, M. J. and Teitelbaum, H.: Observation and Analysis of a Large Amplitude Mountain Wave Event over the Antarctic Peninsula, J. Geophys. Res., 112, D21103, doi:10.1029/2006JD008368, 2007.

Alexander, M. J. and Teitelbaum, H.: Three-dimensional properties of Andes mountain waves observed by satellite: A case study, J. Geophys. Res., 116, D23110, doi:10.1029/2011JD016151, 2011.

Alexander, M. J., Eckermann, S. D., Broutman, D., and Ma, J.: Momentum flux estimates for South Georgia Island mountain waves in the stratosphere observed via satellite, Geophys. Res. Lett., 36, L12816, doi:10.1029/2009GL038587, 2009.

Alexander, M. J., Geller, M., McLandress, C., Polavarapu, S., Preusse, P., Sassi, F., Sato, K., Eckermann, S., Ern, M., Hertzog, A., Kawatani, Y., Pulido, M., Shaw, T. A., Sigmond, M., Vincent, R., and Watanabe, S.: Recent developments in gravity-wave effects in climate models and the global distribution of gravitywave momentum flux from observations and models, Q. J. Roy. Meteor. Soc., 136, 1103-1124, 2010.

Alexander, S. P., Klekociuk, A. R., and Tsuda, T.: Gravity wave and orographic wave activity observed around the Antarctic and Arctic stratospheric vortices by the COSMIC GPSRO satellite constellation, J. Geophys. Res., 114, D17103, doi:10.1029/2009JD011851, 2009.

Aumann, H. H., Gregorich, D. T., Gaiser, S. L., Hagan, D. F., Pagano, T. S., Strow, L. L., and Ting, D.: AIRS Level 1B Algorithm Thoretical Basis Document (ATBD) Part 1 (IR), Tech. rep., NASA, available at: http://eospso.gsfc.nasa.gov/eos_homepage/ for_scientists/atbd/docs/AIRS/AIRS_L1B_ATBD_Part_1.pdf (last access: 26 June 2014), 2000.

Aumann, H. H., Chahine, M. T., Gautier, C., Goldberg, M. D., Kalnay, E., McMillin, L. M., Revercomb, H., Rosenkranz, P. W., Smith, W. L., Staelin, D. H., Strow, L. L., and Susskind, J.: AIRS/AMSU/HSB on the Aqua Mission: Design, Science Objective, Data Products, and Processing Systems, in: IEEE Trans. Geosci. Remote Sens., 41, 253-264, 2003.

Aumann, H. H., DeSouza-Machado, S. G., and Behrangi, A.: Deep convective clouds at the tropopause, Atmos. Chem. Phys., 11, 1167-1176, doi:10.5194/acp-11-1167-2011, 2011.

Ayarzagüena, B., Langematz, U., and Serrano, E.: Tropospheric forcing of the stratosphere: A comparative study of the two different major stratospheric warmings in 2009 and 2010, J. Geophys. Res., D18114, doi:10.1029/2010JD015023, 2011.

Baumgaertner, A. J. G. and McDonald, A. J.: A gravity wave climatology for Antarctica compiled from Challenging Minisatellite Payload/Global Positioning System (CHAMP/GPS) radio occultations, J. Geophys. Res., 112, D05103, doi:10.1029/2006JD007504, 2007.

Bloom, H.: The Cross-track Infrared Sounder (CrIS): a sensor for operational meteorological remote sensing, in: Geoscience and Remote Sensing Symposium, 2001. IGARSS '01. IEEE 2001 International, vol. 3, 1341-1343, doi:10.1109/IGARSS.2001.976838, 2001.

Blumstein, D., Chalon, G., Carlier, T., Buil, C., Hebert, P., Maciaszek, T., Ponce, G., Phulpin, T., Tournier, B., Simeoni, D., Astruc, P., Clauss, A., Kayal, G., and Jegou, R.: IASI instrument: technical overview and measured performances, in: Proc. SPIE, vol. 5543, 196-207, 2004.

Blumstein, D., Tournier, B., Cayla, F. R., Phulpin, T., Fjortoft, R., Buil, C., and Ponce, G.: In-flight performance of the infrared atmospheric sounding interferometer (IASI) on METOP-A, vol. 6684, 66840H-66840H-12, doi:10.1117/12.734162, 2007.

Chahine, M. T., Pagano, T. S., Aumann, H. H., Atlas, R., Barnet, C., Blaisdell, J., Chen, L., Divakarla, M., Fetzer, E. J., Goldberg, M., Gautier, C., Granger, S., Hannon, S., Irion, F. W., Kakar, R., Kalnay, E., Lambrigtsen, B. H., Lee, S., Marshall, J. L., McMillan, W. W., McMillin, L., Olsen, E. T., Revercomb, H., Rosenkranz, P., Smith, W. L., Staelin, D., Strow, L. L., Susskind, J., Tobin, D., Wolf, W., and Zhou, L.: AIRS: improving weather forecasting and providing new data on greenhouse gases, B. Am. Meteorol. Soc., 87, 911-926, 2006.

Charlton, A. J. and Polvani, L. M.: A New Look at Stratospheric Sudden Warmings. Part I: Climatology and Modeling Benchmarks, J. Climate, 20, 449-469, 2007. 
Choi, H. J., Chun, H. Y., Gong, J., and Wu, D. L.: Comparison of gravity wave temperature variances from raybased spectral parameterization of convective gravity wave drag with AIRS observations, J. Geophys. Res., 117, D05115, doi:10.1029/2011JD016900, 2012.

Clerbaux, C., Boynard, A., Clarisse, L., George, M., Hadji-Lazaro, J., Herbin, H., Hurtmans, D., Pommier, M., Razavi, A., Turquety, S., Wespes, C., and Coheur, P.-F.: Monitoring of atmospheric composition using the thermal infrared IASI/MetOp sounder, Atmos. Chem. Phys., 9, 6041-6054, doi:10.5194/acp-9-6041-2009, 2009

Dee, D. P., Uppala, S. M., Simmons, A. J., Berrisford, P., Poli, P., Kobayashi, S., Andrae, U., Balmaseda, M. A., Balsamo, G., Bauer, P., Bechtold, P., Beljaars, A. C. M., van de Berg, L., Bidlot, J., Bormann, N., Delsol, C., Dragani, R., Fuentes, M., Geer, A. J., Haimberger, L., Healy, S. B., Hersbach, H., Hólm, E. V., Isaksen, L., Kållberg, P., Köhler, M., Matricardi, M., McNally, A. P., Monge-Sanz, B. M., Morcrette, J.-J., Park, B.-K., Peubey, C., de Rosnay, P., Tavolato, C., Thépaut, J.-N., and Vitart, F.: The ERA-Interim reanalysis: configuration and performance of the data assimilation system, Q. J. Roy. Meteor. Soc., 137, 553-597, 2011

de la Torre, A., Alexander, P., Hierro, R., Llamedo, P., Rolla, A., Schmidt, T., and Wickert, J.: Large-amplitude gravity waves above the southern Andes, the Drake Passage, and the Antarctic Peninsula, J. Geophys. Res., 117, D02106, doi:10.1029/2011JD016377, 2012.

de Souza-Machado, S., Strow, L. L., Hannon, S. E., Motteler, H., López-Puertas, M., Funke, B., and Edwards, D. P.: Fast Forward Radiative Transfer Modeling of $4.3 \mu \mathrm{m}$ Non-Local Thermodynamic Equilibrium effects for the Aqua/AIRS Infrared Temperature Sounder, Geophys. Res. Lett., 34, L01802, doi:10.1029/2006GL026684, 2006.

Dörnbrack, A., Leutbecher, M., Kivi, R., and Kyrö, E.: Mountainwave-induced record low stratospheric temperatures above northern Scandinavia, Tellus, 51, 951-963, 1999.

Durran, D. R. and Klemp, J. B.: Another look at downslope winds. Part II: nonlinear amplification beneath wave-overturning layers, J. Atmos. Sci., 44, 3402-3412, 1987.

Eckermann, S. D. and Wu, D. L.: Satellite detection of orographic gravity-wave activity in the winter subtropical stratosphere over Australia and Africa, Geophys. Res. Lett., 39, L21807, doi:10.1029/2012GL053791, 2012.

Eckermann, S. D., Wu, D. L., Doyle, J. D., Burris, J. F., McGee, T. J., Hostetler, C. A., Coy, L., Lawrence, B. N., Stephens, A., McCormack, J. P., and Hogan, T. F.: Imaging gravity waves in lower stratospheric AMSU-A radiances, Part 2: Validation case study, Atmos. Chem. Phys., 6, 3343-3362, doi:10.5194/acp-63343-2006, 2006.

Eckermann, S. D., Ma, J., Wu, D. L., and Broutman, D.: A threedimensional mountain wave imaged in satellite radiance throughout the stratosphere: Evidence of the effects of directional wind shear, Q. J. Roy. Meteor. Soc., 133, 1959-1975, 2007.

Eckermann, S. D., Hoffmann, L., Höpfner, M., Wu, D. L., and Alexander, M. J.: Antarctic NAT PSC belt of June 2003: Observational validation of the mountain wave seeding hypothesis, Geophys. Res. Lett., 36, L02807, doi:10.1029/2008GL036629, 2009.
Elliott, D. A., Weiler, M., Manning, E. M., Pagano, T. S., Broberg, S. E., and Aumann, H. H.: Calibration status of the Atmospheric Infrared Sounder after eleven years in operation, in: Proc. SPIE, vol. 8866, doi:10.1117/12.2024585, 2013.

Ern, M., Preusse, P., Alexander, M. J., and Warner, C. D.: Absolute values of gravity wave momentum flux derived from satellite data, J. Geophys. Res., 109, D20103, doi:10.1029/2004JD004752, 2004.

Fritts, D. C. and Alexander, M. J.: Gravity wave dynamics and effects in the middle atmosphere, Rev. Geophys., 41, 1003, doi:10.1029/2001RG000106, 2003.

Geller, M. A., Alexander, M. J., Love, P. T., Bacmeister, J., Ern, M., Hertzog, A., Manzini, E., Preusse, P., Sato, K., Scaife, A. A., and Zhou, T.: A comparison between gravity wave momentum fluxes in observations and climate models, J. Climate, 26, 6383-6405, 2013.

Gibbs, C. R. V.: Remote islands of the Southern Indian ocean, Scott. Geogr. Mag., 61, 9-16, doi:10.1080/00369224508735277, 1945.

Gong, J., Wu, D. L., and Eckermann, S. D.: Gravity wave variances and propagation derived from AIRS radiances, Atmos. Chem. Phys., 12, 1701-1720, doi:10.5194/acp-12-1701-2012, 2012

Grimsdell, A. W., Alexander, M. J., May, P. T., and Hoffmann, L.: Model study of waves generated by convection with direct validation via satellite, J. Atmos. Sci., 67, 1617-1631, 2010.

Hecht, J. H., Alexander, M. J., Walterscheid, R. L., Gelinas, L. J., Vincent, R. A., MacKinnon, A. D., Woithe, J. M., May, P. T., Skinner, W. R., Mlynczak, M. G., and Russell III, J. M.: Imaging of atmospheric gravity waves in the stratosphere and upper mesosphere using satellite and ground-based observations over Australia during the TWPICE campaign, J. Geophys. Res., 114, D18123, doi:10.1029/2008JD011259, 2009.

Hertzog, A., Boccara, G., Vincent, R. A., Vial, F., and Cocquerez, P.: Estimation of gravity wave momentum flux and phase speeds from quasi-Lagrangian stratospheric balloon flights. Part II: Results from the Vorcore campaign in Antarctica, J. Atmos. Sci., 65, 3056-3070, 2008.

Hilton, F., Armante, R., August, T., Barnet, C., Bouchard, A., Camy-Peyret, C., Capelle, V., Clarisse, L., Clerbaux, C., Coheur, P. ., Collard, A., Crevoisier, C., Dufour, G., Edwards, D., Faijan, F., Fourrié, N., Gambacorta, A., Goldberg, M., Guidard, V., Hurtmans, D., Illingworth, S., Jacquinet-Husson, N., Kerzenmacher, T., Klaes, D., Lavanant, L., Masiello, G., Matricardi, M., McNally, A., Newman, S., Pavelin, E., Payan, S., Péquignot, E., Peyridieu, S., Phulpin, T., Remedios, J., Schlüssel, P., Serio, C., Strow, L., Stubenrauch, C., Taylor, J., Tobin, D., Wolf, W., and Zhou, D.: Hyperspectral earth observation from IASI, B. Am. Meteorol. Soc., 93, 347-370, 2012.

Hoffmann, L. and Alexander, M. J.: Retrieval of stratospheric temperatures from Atmospheric Infrared Sounder radiance measurements for gravity wave studies, J. Geophys. Res., 114, D07105, doi:10.1029/2008JD011241, 2009.

Hoffmann, L. and Alexander, M. J.: Occurrence frequency of convective gravity waves during the North American thunderstorm season, J. Geophys. Res., 115, D20111, doi:10.1029/2010JD014401, 2010.

Hoffmann, L., Xue, X., and Alexander, M. J.: A global view of stratospheric gravity wave hotspots located with Atmospheric Infrared Sounder observations, J. Geophys. Res., 118, 416-434, doi:10.1029/2012JD018658, 2013. 
Holton, J. R.: The role of gravity wave induced drag and diffusion on the momentum budget of the mesosphere, J. Atmos. Sci., 39, 791-799, 1982.

Holton, J. R.: The Influence of Gravity Wave Breaking on the General Circulation of the Middle Atmosphere, J. Atmos. Sci., 40, 2497-2507, 1983.

Höpfner, M., Larsen, N., Spang, R., Luo, B. P., Ma, J., Svendsen, S. H., Eckermann, S. D., Knudsen, B., Massoli, P., Cairo, F., Stiller, G., v. Clarmann, T., and Fischer, H.: MIPAS detects Antarctic stratospheric belt of NAT PSCs caused by mountain waves, Atmos. Chem. Phys., 6, 1221-1230, doi:10.5194/acp-6-1221-2006, 2006.

Illingworth, S. M., Remedios, J. J., and Parker, R. J.: Intercomparison of integrated IASI and AATSR calibrated radiances at 11 and $12 \mu \mathrm{m}$, Atmos. Chem. Phys., 9, 6677-6683, doi:10.5194/acp-96677-2009, 2009.

Immerkær, J.: Fast noise variance estimation, Comput. Vis. Image Und., 64, 300-302, 1996.

Jiang, J. H., Eckermann, S. D., Wu, D. L., Hocke, K., Wang, B., Ma, J., and Zhang, Y.: Seasonal variation of gravity wave sources from satellite observation, Adv. Space Res., 35, 19251932, 2005.

Jiang, J. H., Eckermann, S. D., Wu, D. L., and Wang, D. Y.: Interannual variation of gravity waves in the Arctic and Antarctic winter middle atmosphere, Adv. Space Res., 38, 2418-2423, 2006.

Jiang, Q., Doyle, J. D., Reinecke, A., Smith, R. B., and Eckermann, S. D.: A Modeling Study of Stratospheric Waves over the Southern Andes and Drake Passage, J. Atmos. Sci., 70, 1668-1689, 2013

Kim, S., Chun, H., and Wu, D. L.: A study on stratospheric gravity waves generated by Typhoon Ewiniar: Numerical simulations and satellite observations, J. Geophys. Res., 114, D22104, doi:10.1029/2009JD011971, 2009.

Lambert, A., Santee, M. L., Wu, D. L., and Chae, J. H.: A-train CALIOP and MLS observations of early winter Antarctic polar stratospheric clouds and nitric acid in 2008, Atmos. Chem. Phys., 12, 2899-2931, doi:10.5194/acp-12-2899-2012, 2012.

Larar, A. M., Smith, W. L., Zhou, D. K., Liu, X., Revercomb, H., Taylor, J. P., Newman, S. M., and Schlüssel, P.: IASI spectral radiance validation inter-comparisons: case study assessment from the JAIVEx field campaign, Atmos. Chem. Phys., 10, 411-430, doi:10.5194/acp-10-411-2010, 2010.

Limpasuvan, V., Wu, D. L., Alexander, M. J., Xue, M., Hu, M., Pawson, S., and Perkins, J. R.: Stratospheric gravity wave simulation over Greenland during 24 January 2005, J. Geophys. Res., 112, D10115, doi:10.1029/2006JD007823, 2007.

Lindzen, R. S.: Turbulence and stress due to gravity wave and tidal breakdown, J. Geophys. Res., 86, 9707-9714, 1981.

McDonald, A. J., George, S. E., and Woollands, R. M.: Can gravity waves significantly impact PSC occurrence in the Antarctic?, Atmos. Chem. Phys., 9, 8825-8840, doi:10.5194/acp-9-8825-2009, 2009.

Nastrom, G. D. and Fritts, D. C.: Sources of mesoscale variability of gravity waves. Part I: topographic excitation, J. Atmos. Sci., 49, 101-110, 1992.

Niranjan Kumar, K., Ramkumar, T. K., and Krishnaiah, M.: Analysis of large-amplitude stratospheric mountain wave event observed from the AIRS and MLS sounders over the west- ern Himalayan region, J. Geophys. Res., 117, D22102, doi:10.1029/2011JD017410, 2012.

Noel, V. and Pitts, M.: Gravity wave events from mesoscale simulations, compared to polar stratospheric clouds observed from spaceborne lidar over the Antarctic Peninsula, J. Geophys. Res., 117, D11207, doi:10.1029/2011JD017318, 2012.

Orr, A., Hosking, J. S., Hoffmann, L., Keeble, J., Dean, S. M., Roscoe, H. K., Abraham, N. L., Vosper, S., and Braesicke, P.: Inclusion of mountain wave-induced cooling for the formation of PSCs over the Antarctic Peninsula in a chemistryclimate model, Atmos. Chem. Phys. Discuss., 14, 18277-18314, doi:10.5194/acpd-14-18277-2014, 2014.

Pagano, T. S., Aumann, H. H., Hagan, D. E., and Overoye, K.: Prelaunch and in-flight radiometric calibration of the Atmospheric Infrared Sounder (AIRS), in: IEEE Trans. Geosci. Remote Sens., 41, 265-273, 2003.

Pagano, T. S., Aumann, H. H., Schindler, R., Elliott, D., Broberg, S., Overoye, K., and Weiler, M. H.: Absolute radiometric calibration accuracy of the Atmospheric Infrared Sounder (AIRS), in: Proc. SPIE, vol. 7081, doi:10.1117/12.795445, 2008.

Pfister, L., Starr, W., Craig, R., Loewenstein, M., and Legg, M.: Small-Scale Motions Observed by Aircraft in the Tropical Lower Stratosphere: Evidence for Mixing and its Relationship to LargeScale Flows, J. Atmos. Sci., 43, 3210-3225, 1986.

Plougonven, R., Hertzog, A., and Teitelbaum, H.: Observations and simulations of a large-amplitude mountain wave breaking over the Antarctic Peninsula, J. Geophys. Res., 113, D16113, doi:10.1029/2007JD009739, 2008.

Preusse, P., Eckermann, S. D., and Ern, M.: Transparency of the atmosphere to short horizontal wavelength gravity waves, J. Geophys. Res., 113, D24104, doi:10.1029/2007JD009682, 2008.

Preusse, P., Eckermann, S. D., Ern, M., Oberheide, J., Picard, R. H., Roble, R. G., Riese, M., Russell III, J. M., and Mlynczak, M. G.: Global ray tracing simulations of the SABER gravity wave climatology, J. Geophys. Res., 114, D08126, doi:10.1029/2008JD011214, 2009a.

Preusse, P., Schroeder, S., Hoffmann, L., Ern, M., Friedl-Vallon, F., Ungermann, J., Oelhaf, H., Fischer, H., and Riese, M.: New perspectives on gravity wave remote sensing by spaceborne infrared limb imaging, Atmos. Meas. Tech., 2, 299-311, doi:10.5194/amt-2-299-2009, 2009b.

Scaife, A. A., Butchart, N., Warner, C. D., Stainforth, D., and Norton, W.: Realistic quasi-biennial osciallations in a simulation of the global climate, Geophys. Res. Lett., 27, 3481-3484, 2000.

Simeoni, D., Astruc, P., Miras, D., Alis, C., Andreis, O., Scheidel, D., Degrelle, C., Nicol, P., Bailly, B., Guiard, P., Clauss, A., Blumstein, D., Maciaszek, T., Chalon, G., Carlier, T., and Kayal, G.: Design and development of IASI instrument, in: Proc. SPIE, vol. 5543, 208-219, 2004.

Smith, R. B.: On severe downslope winds., J. Atmos. Sci., 42, 2597 2603, 1985.

Smith Sr., W. L., Revercomb, H., Bingham, G., Larar, A., Huang, H., Zhou, D., Li, J., Liu, X., and Kireev, S.: Technical Note: Evolution, current capabilities, and future advance in satellite nadir viewing ultra-spectral IR sounding of the lower atmosphere, Atmos. Chem. Phys., 9, 5563-5574, doi:10.5194/acp-9-5563-2009, 2009. 
Stockwell, R. G., Mansinha, L., and Lowe, R.: Localization of the complex spectrum: the $\mathrm{S}$ transform, IEEE Trans. Signal Process., 44, 998-1001, 1996.

Tsuda, T., Murayama, Y., Wiryosumarto, H., Harijono, S. W. B., and Kato, S.: Radiosonde observations of equatorial atmosphere dynamics over Indonesia. 2. Characteristics of gravity waves, J. Geophys. Res., 99, 10507-10516, 1994.

Vadas, S. L., Fritts, D. C., and Alexander, M. J.: Mechanism for the Generation of Secondary Waves in Wave Breaking Regions, J. Atmos. Sci., 60, 194-214, 2003.

Vincent, R. A. and Alexander, M. J.: Gravity waves in the tropical lower stratosphere: An observational study of seasonal and interannual variability, J. Geophys. Res., 105, 17971-17982, 2000.

Vincent, R. A., Hertzog, A., Boccara, G., and Vial, F.: Quasi-Lagrangian superpressure balloon measurements of gravity-wave momentum fluxes in the polar stratosphere of both hemispheres, Geophys. Res. Lett., 34, L19804, doi:10.1029/2007GL031072, 2007.

$\mathrm{Wu}$, D. L.: Mesoscale gravity wave variances from AMSU-A radiances, Geophys. Res. Lett., 31, L12114, doi:10.1029/2004GL019562, 2004.

Wu, D. L. and Eckermann, S. D.: Global gravity wave variances from Aura MLS: characteristics and interpretation, J. Atmos. Sci., 65, 3695-3718, 2008.
Wu, D. L. and Jiang, J. H.: MLS observations of atmospheric gravity waves over Antarctica, J. Geophys. Res., 107, 4773, doi:10.1029/2002JD002390, 2002.

Wu, D. L. and Waters, J. W.: Gravity-wave-scale temperature fluctuations seen by the UARS MLS, Geophys. Res. Lett., 23, 32893292, 1996.

Wu, D. L. and Zhang, F.: A study of mesoscale gravity waves over the North Atlantic with satellite observations and a mesoscale model, J. Geophys. Res., 109, D22104, doi:10.1029/2004JD005090, 2004.

Wu, D. L., Preusse, P., Eckermann, S. D., Jiang, J. H., de la Torre Juarez, M., Coy, L., Lawrence, B., and Wang, D. Y.: Remote sounding of atmospheric gravity waves with satellite limb and nadir techniques, Adv. Space Res., 37, 2269-2277, 2006.

Yue, J., Hoffmann, L., and Alexander, M. J.: Simultaneous observations of convective gravity waves from a ground-based airglow imager and the AIRS satellite experiment, J. Geophys. Res., 118, 3178-3191, doi:10.1002/jgrd.50341, 2013.

Yue, J., Thurairajah, B., Hoffmann, L., Alexander, M. J., Chandran, A., Taylor, M. J., Russell III, J. M., Randall, C. E., and Bailey, S. M.: Concentric gravity waves in polar mesospheric clouds from the Cloud Imaging and Particle Size experiment, J. Geophys. Res., 119, 5115-5127, doi:10.1002/2013JD021385, 2014. 